\title{
SWOT Spatial Scales in the Western Mediterranean Sea Derived from Pseudo-Observations and an Ad Hoc Filtering
}

\author{
Laura Gómez-Navarro 1,2,* (D), Ronan Fablet ${ }^{3}$, Evan Mason ${ }^{1}$ (D), Ananda Pascual ${ }^{1}$, \\ Baptiste Mourre ${ }^{4}$, Emmanuel Cosme ${ }^{2}$ and Julien Le Sommer ${ }^{2}$ (D) \\ 1 Institut Mediterrani d'Estudis Avançats (IMEDEA) (CSIC-UIB), 07190 Esporles, Illes Balears, Spain; \\ evanmason@gmail.com (E.M.); ananda.pascual@imedea.uib-csic.es (A.P.) \\ 2 Univ. Grenoble Alpes, CNRS, IRD, Grenoble INP, IGE, 38000 Grenoble, France; \\ Emmanuel.Cosme@univ-grenoble-alpes.fr (E.C.); julien.lesommer@univ-grenoble-alpes.fr (J.L.S.) \\ 3 Institut Mines-Télécom, Telecom-Bretagne, UMR 6285 labSTICC, 29238 Brest, France; \\ ronan.fablet@imt-atlantique.fr \\ 4 Balearic Islands Coastal Observing and Forecasting System (SOCIB), 07121 Palma de Mallorca, \\ Illes Balears, Spain; bmourre@socib.es \\ * Correspondence: lauragomnav@gmail.com
}

Received: 28 March 2018; Accepted: 28 March 2018; Published: 12 April 2018

\begin{abstract}
The aim of this study is to assess the capacity of the Surface Water Ocean Topography (SWOT) satellite to resolve fine scale oceanic surface features in the western Mediterranean. Using as input the Sea Surface Height (SSH) fields from a high-resolution Ocean General Circulation Model (OGCM), the SWOT Simulator for Ocean Science generates SWOT-like outputs along a swath and the nadir following the orbit ground tracks. Given the characteristic temporal and spatial scales of fine scale features in the region, we examine temporal and spatial resolution of the SWOT outputs by comparing them with the original model data which are interpolated onto the SWOT grid. To further assess the satellite's performance, we derive the absolute geostrophic velocity and relative vorticity. We find that instrument noise and geophysical error mask the whole signal of the pseudo-SWOT derived dynamical variables. We therefore address the impact of removal of satellite noise from the pseudo-SWOT data using a Laplacian diffusion filter, and then focus on the spatial scales that are resolved within a swath after this filtering. To investigate sensitivity to different filtering parameters, we calculate spatial spectra and root mean square errors. Our numerical experiments show that noise patterns dominate the spectral content of the pseudo-SWOT fields at wavelengths below $60 \mathrm{~km}$. Application of the Laplacian diffusion filter allows recovery of the spectral signature within a swath down to the 40-60 km wavelength range. Consequently, with the help of this filter, we are able to improve the observation of fine scale oceanic features in pseudo-SWOT data, and in the estimation of associated derived variables such as velocity and vorticity.
\end{abstract}

Keywords: satellite altimetry; SWOT; western Mediterranean Sea; fine scale; SWOT simulator; ROMS model; filtering

\section{Introduction}

The Surface Water and Ocean Topography (SWOT) satellite mission is a joint mission by the National Aeronautics and Space Administration (NASA) and the Centre National d'Études Spatiales (CNES), with contributions from the UK and Canadian Space Agencies [1]. Presently, the satellite's launch is planned for 2021 [2]. It will provide water elevation maps for oceanographic and hydrological purposes $[3,4]$. The novelty of this satellite is that it carries a wide-swath altimeter with unprecedented 
horizontal resolution and global coverage. On the other hand, the associated irregular temporal sampling will constitute a challenge for the exploitation of the data. SWOT will have a 21-day repeat cycle and the revisit time will vary from approximately 10 days at the equator to two days at the poles [5,6]. This implies temporal variability in spatial coverage as the number of observations per repeat cycle will increase with latitude. Moreover, there will also be a temporal variability within a cycle. During each cycle, there are periods of time with a higher temporal sampling. This is due to a longer revisit time so that SWOT also fulfills its hydrological objectives by providing coverage of the bulk of the global land surface [7]. In satellite measurements, there is always a compromise between spatial and temporal resolution. As SWOT aims for global coverage, i.e., high spatial resolution, we lose in temporal resolution (SWOT's repeat cycle will be longer than, for example, the 10-day repeat cycle of the Jason altimeter satellites [8]).

One of the primary oceanographic objectives of the SWOT mission is to characterize the ocean meso- and submesoscale circulation [9] determined from ocean surface topography at spatial resolutions of $15 \mathrm{~km}$ (spatial resolution is defined to be perturbation wavelength in the oceanographic context). The resolution capacity of current along-track one-dimensional altimeter data, depending on the altimeter, has been found to be between 40 and $50 \mathrm{~km}$ at western boundary currents and between 70 and $110 \mathrm{~km}$ at the eastern basins [10]. Two-dimensional gridded products based on the altimetric constellation allow for mapping wavelengths down to $200 \mathrm{~km}$ [11]. The SWOT mission is expected to allow to capture wavelengths down to $15 \mathrm{~km}$ on its two-dimensional swaths [12], therefore increasing substantially the resolution capacity of present-day altimeter data. The possibility of characterizing the submesoscale is a major breakthrough. While the mesoscale has historically received a lot of attention [13], the submesoscale has previously been out of reach. Theoretical calculations and advanced modeling suggest that submesoscale processes are key to understanding ocean fluxes [14-16]. A pertinent example is the occurrence of mid-ocean plankton blooms [17].

In the Mediterranean Sea, intense mesoscale and submesoscale variability interact across sub-basin and basin scales [18-20]. This variability has an indirect impact on the Atlantic Ocean circulation due to exchange through the Strait of Gibraltar and, subsequently, influence on the great ocean conveyor belt [21-23]. Three scales of motion are therefore overlaid, making an amalgam of intricate processes that require high resolution and can help assess the potential impact that SWOT will have on the study of processes occurring at different scales.

Understanding small scale variability in the Mediterranean Sea is important as it is a region with intrinsically smaller spatial scales than those found in other parts of the world ocean at similar latitudes. Ref. [24] showed that the grid resolution necessary to resolve the first baroclinic deformation radius in the Mediterranean is around $1 / 16^{\circ}$, whilst in the Atlantic Ocean at the same latitude it is only $1 / 6^{\circ}$. This implies that smaller structures need to be resolved in the Mediterranean Sea compared to the mid-latitudes of the Atlantic Ocean. This is further demonstrated by [25] who show that lower values of the first baroclinic Rossby radius of deformation are present in the western Mediterranean Sea. These values are approximately between 2 and $16 \mathrm{~km}$, in comparison with a 20-30 km range found at mid-latitudes of the Atlantic Ocean [26]. The Mediterranean values are actually closer to the values found in the Arctic Ocean [27].

The western Mediterranean Sea is one of the areas of the global ocean that will be sampled during the SWOT fast-sampling phase [28]. This phase covers the first 60-90 days after launch, during which the satellite will provide daily high resolution Sea Surface Height (SSH) measurements over a limited repeated orbit for purposes of calibration/validation of the SWOT sensor/instrument.

The goal of this study is to assess the capacity of SWOT to resolve the fine scales in the western Mediterranean. Our first objective is to generate pseudo-SWOT data from numerical model outputs in this region in order to understand its temporal and spatial sampling pattern in this area. We then apply a noise-reduction processing technique to pseudo-SWOT data to find out the spatial scales that SWOT may ultimately be able to resolve. Given SWOT's irregular time sampling and consequent variable spatial coverage, in this paper, we focus on the spatial scales resolved within a swath. 


\section{Data and Methods}

\subsection{The SWOT Simulator}

With a view to characterizing the potential of SWOT-derived SSH data, we consider a simulation-based framework using the SWOT Simulator for Ocean Science (version 1). This simulator accounts for both SWOT space-time sampling patterns and noise processes. Using as input the SSH fields from an Oceanic General Circulation Model (OGCM), the SWOT simulator generates SWOT-like outputs along a ground swath and the nadir following the orbit ground tracks [29]. Hereinafter, we refer to these outputs as SSH outputs. Note that these simulated fields correspond to Absolute Dynamic Topography (ADT) values in altimetric terminology.

A flowchart of the simulator workflow is provided in Figure 1. Two features should be pointed out. Grid files, generated in the first step of the flowchart, account for the planned orbit of the satellite and the specified domain. Instrument noise and geophysical errors are added during the last step of the flowchart, following recent technical characteristics established by the SWOT project team [29]. Instrument noise is composed of Ka-band Radar Interferometer (KaRIN) noise, roll, phase, baseline dilation and timing errors (see [30]). In this version of the simulator, the only geophysical error is associated with the wet troposphere. Therefore, it is important to keep in mind that additional noise patterns, such as sea state bias [29] or the effects of internal waves [2] are not accounted for in the generated pseudo-SWOT data.

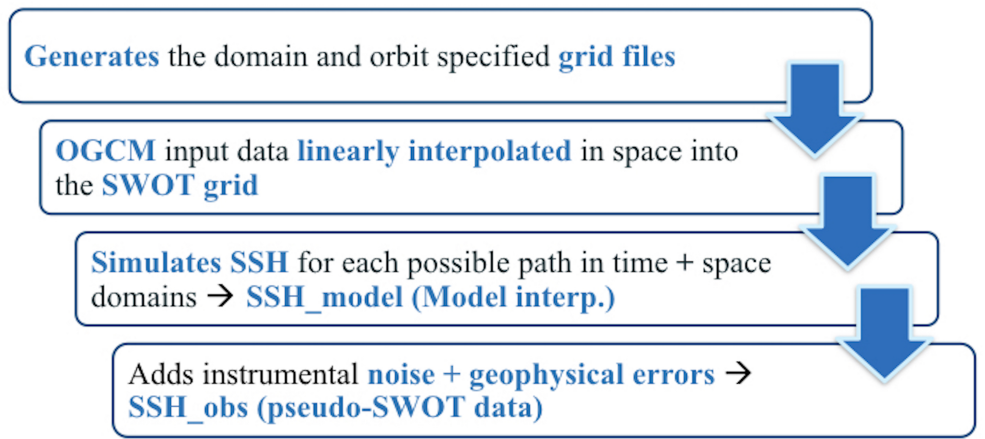

Figure 1. Flowchart of the SWOT simulator procedure.

For more details on the instrument noise and geophysical errors added by the SWOT simulator, see Appendix B.

\subsection{Input Data: The Western Mediterranean OPerational (WMOP) Model}

A high resolution OGCM of the western Mediterranean region provides input data for the SWOT simulator. We used the WMOP model [31] developed at SOCIB (Balearic Islands Coastal Observing and Forecasting System). More specifically, we consider a 7-year free run simulation of the model spanning the period 2009 - 2015, with spatial coverage from the Strait of Gibraltar to the Sardinia Channel (Figure 2). WMOP is a regional configuration of the Regional Oceanic Model System (ROMS) model [32] with a spatial resolution of approximately $2 \mathrm{~km}$. WMOP is forced with high resolution atmospheric forcing (HIRLAM model from the Spanish Meteorological Agency AEMET), with temporal resolution of $3 \mathrm{~h}$ and spatial resolution of $5 \mathrm{~km}$. These features make WMOP a suitable choice to evaluate the potential of SWOT-derived SSH data to resolve mesoscale processes in the western Mediterranean Sea. The presence of fine scale features of a few kilometers is illustrated in Figure 2. In Figure 2, we show snapshots of model relative vorticity (normalized by f) for days corresponding to pass 15 (Figure 2, left) and pass 168 (Figure 2, right) of cycle 2 of the SWOT orbit (see Figure 3). 

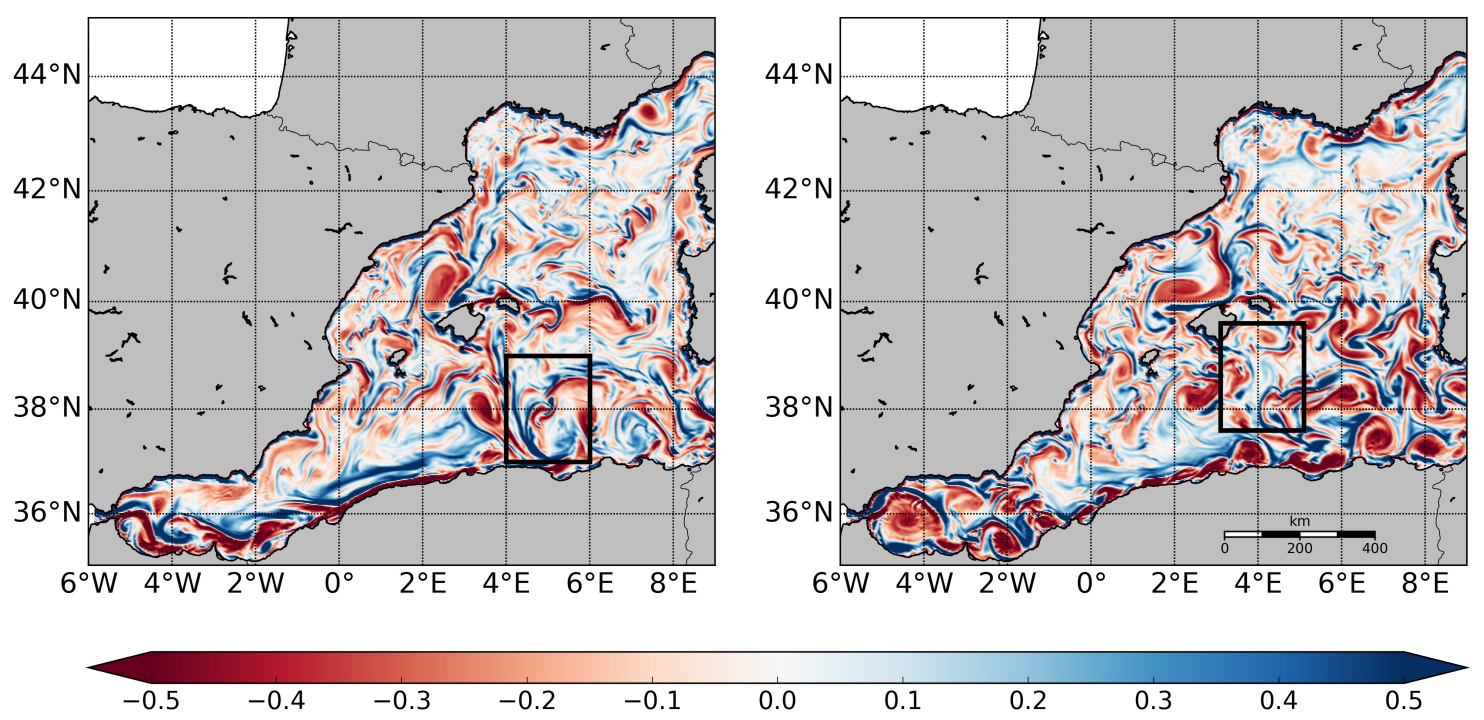

Figure 2. WMOP relative vorticity normalized by f on 23 January 2009 (left) and 3 February 2009 (right). Black boxes indicate the two regions studied in Section 3: box 1, pass 15 (left) and box 2, pass 168 (right).

\subsection{Analysis and Processing of SWOT-Derived SSH Data}

\subsubsection{Geostrophic Velocity and Vorticity}

Zonal $\left(u_{g}\right)$ and meridional $\left(v_{g}\right)$ (with respect to the SWOT grid) surface geostrophic velocity components are calculated as:

$$
\begin{gathered}
u_{g}=-\frac{g}{f} \frac{\partial \eta}{\partial y} \\
v_{g}=\frac{g}{f} \frac{\partial \eta}{\partial x}
\end{gathered}
$$

where $g$ is the gravitational acceleration, $f$ the Coriolis parameter and $\eta$ the sea level elevation.

The absolute geostrophic velocity $\left(V_{g}\right)$ is obtained with:

$$
V_{g}=\sqrt{u_{g}+v_{g}^{2}}
$$

Geostrophic relative vorticity, $\zeta$, is calculated from the zonal and meridional velocities:

$$
\zeta=\frac{\partial v_{g}}{\partial x}-\frac{\partial u_{g}}{\partial y} .
$$

\subsubsection{Noise Filtering}

As illustrated in Section 3, noise greatly affects the computation of the velocities derived from the pseudo-SWOT data. We therefore investigate filtering procedures for noise removal. The geometry of the SWOT data prevents us from using classical Fourier and convolution-based low-pass filters [33]. Fourier-based filters impose circularity constraints, which cannot be fulfilled; the masks associated with convolution-based filters should be significantly smaller than the width of the SWOT swath, which greatly limits low-pass filtering capabilities. We then considered a Partial Derivative Equation (PDE)-based formulation, such that the low-pass filtering results from an iterated Laplacian diffusion:

$$
\partial_{t} a(t, y, x)-\triangle a(t, y, x)=0 \Longleftrightarrow \frac{\partial a}{\partial t}=\frac{\partial^{2} a}{\partial y^{2}}+\frac{\partial^{2} a}{\partial x^{2}}
$$


As the Green's function for the heat equation is a Gaussian kernel, the implementation of this PDE-based diffusion is equivalent to a Gaussian convolution and results in an isotropic filtering, that is to say that the filtering acts equally in all directions [34]. Using a four-neighbourhood discretization of the Laplacian operator, we can deal with missing data (e.g., nadir) or land (e.g., island) pixels. The Laplacian operator comes to compute a local mean over the four neighbours of a given pixel. Withdrawing land pixels and missing data from the computation of this local mean, we can iterate the Laplacian diffusion to reach the expected filtering level for all pixels. Each iteration of the Laplacian diffusion can be regarded as a low-pass filtering with a high cut-off frequency. The selection of the number of iterations of the Laplacian diffusion then allows us to reach lower cut-off frequencies. By contrast, the direct application of two-dimensional low-pass filters for cut-off frequencies in the range $[30 \mathrm{~km}, 60 \mathrm{~km}]$ would result in filter supports in the range $[60 \mathrm{~km}, 120 \mathrm{~km}]$, meaning that no filtering output could be computed for any pixel closer than $30 \mathrm{~km}$ (rest. $60 \mathrm{~km}$ ) from the swath boundaries or a missing data or land pixel. Overall, the filtering level is set by the number of iterations of the Laplacian diffusion and the parameter lambda. This is shown in the following equation, which shows the implementation that we use:

$$
a^{k+1}=a^{k}-\lambda \triangle a^{k}
$$

With this being an iterative method, in contrast to a traditional Gaussian filter, we can apply cut-off wavelengths greater than the width of a half-swath. In Appendix A, we apply the filter to white noise to show how different combinations of the filter's parameters (lambda and number of iterations) are associated with different cut-off wavelengths $\left(\lambda_{\mathrm{c}} s\right)$.

\subsubsection{Filter Evaluation}

To evaluate the performance of the filter and its different parameterizations, the following variables are calculated:

- The radial power spectral density: This variable was calculated to obtain the SWOT spatial spectra. The radially averaged power spectral density (power spectrum) of an image (in our case, the SWOT swath data) is computed.

- The Root Mean Squared Error (RMSE): The RMSE was calculated for the SSH, velocity and vorticity variables as follows:

$$
R M S E=\sqrt{\frac{\sum(\text { data }- \text { estimate })^{2}}{N}}
$$

where $N$ is the number of points. Data is taken to be $\mathrm{SSH}_{\text {model }}$ (or its derived variables, i.e., velocity and vorticity) without filtering. An estimate is taken to be the simulated noisy $\mathrm{SSH}_{o b s}$ fields (or its derived variables) without filtering, and filtered with different $\lambda_{\mathcal{C}} s$. RMSE values are therefore calculated for different estimates.

\section{Results}

\subsection{Spatial and Temporal Sampling}

Pseudo-SWOT data were generated for the full WMOP time period (1 January 2009 to 11 September 2015). This was done for the Science orbit and corresponds to a total of 123 cycles. In a complete cycle, 292 passes are available over the globe, 12 of them crossing our study region (Figure 3). Data were ingested and processed by the SWOT simulator at an across and along track resolution of $2 \mathrm{~km}$. As mentioned in Section 1, one of the specificities of future SWOT data will be their irregular temporal sampling. To better illustrate this, the passes of cycle 2 are plotted in Figure 3 . During each cycle, there are periods of time with a higher temporal sampling. This is due to a longer revisit time so that SWOT also fulfills its hydrological objectives as described in Section 1. For instance, the temporal sampling during cycle 2 is as follows: from day 21.3 to 23.9 during which five passes 
are made; and from day 31.3 to 33.8 during which six passes are made. Then, from day 23.9 to 31.3 and from day 33.8 to 41.2 , there are no measurements. Consequently, during each day within a cycle in this study region, there can be two, one or no passes at all. Even with this irregular sampling and without any processing of the data, the final $\mathrm{SSH}_{o b s}$ map (subplot of day 41.2) allows us to observe some features such as, for example, the signal of the Algerian Current following the north African coastline and several cyclonic and anticyclonic mesoscale eddies.
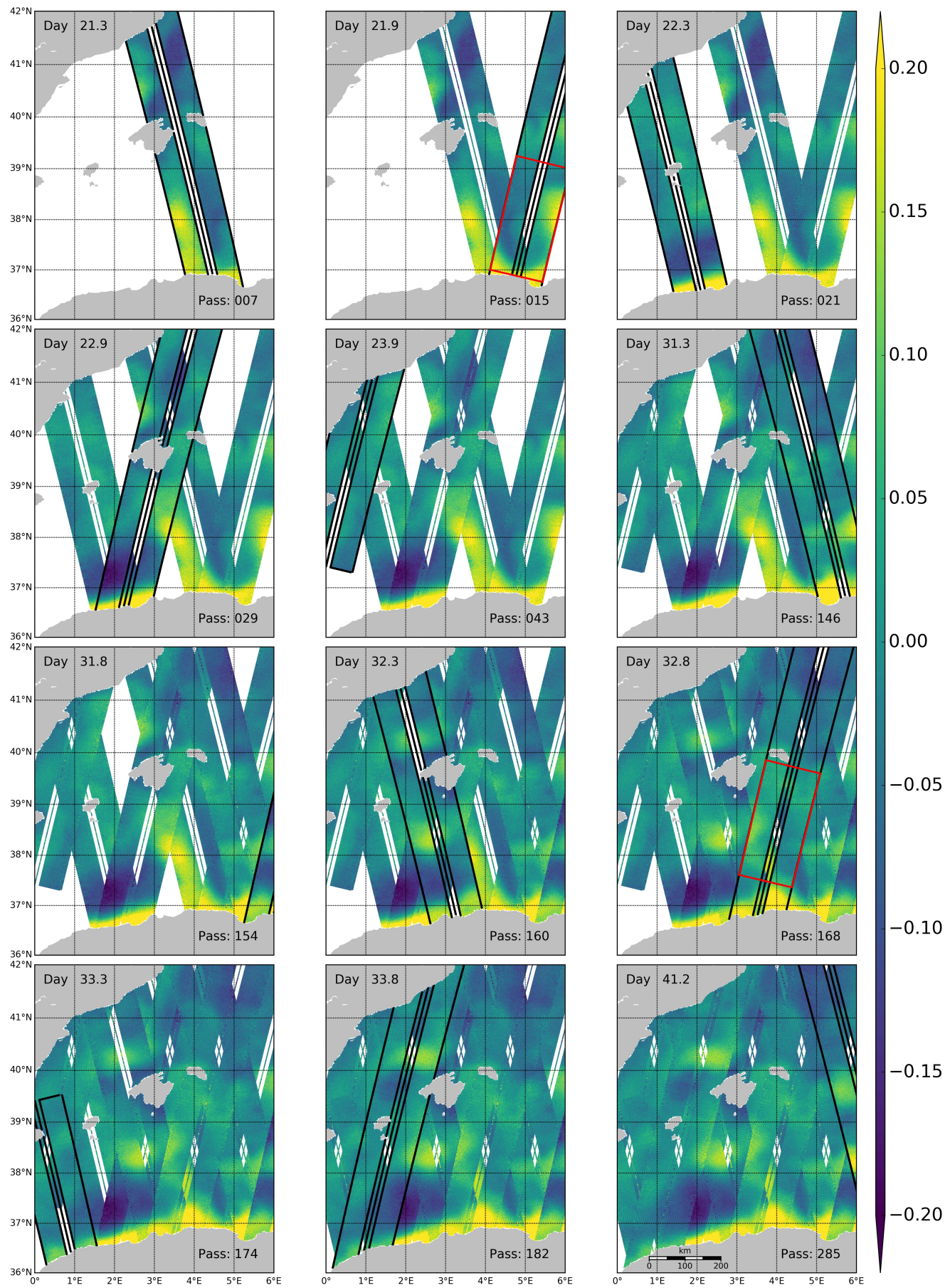

Figure 3. $\mathrm{SSH}_{o b s}(\mathrm{~m})$ obtained for cycle 2. Time increasing from left to right, top to bottom. Days from the beginning of the simulation are shown at the top left corner and the corresponding pass number at the bottom right corner. Outline of the active pass is shown in black. The red boxes show box 1 (pass 15) and box 2 (pass 168). 


\subsection{Pre-Filtering Analysis of Simulator Outputs}

In this study, we focus on the analysis of spatial scales of individual passes. Due to the irregular time sampling of the SWOT data, future studies will be devoted to temporal interpolation of passes. Moreover, prior swath filtering is necessary to determine the quality of the dynamical variables that can be derived from SWOT data, and how it can be improved before combining different swaths for temporal interpolation. As an illustration, we focus on the treatment of two $2^{\mathrm{O}} \times 2^{\mathrm{O}}$ boxes. Box 1 is within pass 15 and was chosen close to the north African coast as it is a region where anticyclonic eddies are shed from the Algerian Current [25,35]. For example, in the snapshot shown in Figure 4, part of an anticyclonic eddy is present on the eastern part of the domain. Box 2 is within pass 168, and this subdomain south of the Balearic island of Menorca was chosen because it contains smaller structures than in box 1 (see Figure 2). In Figure 5, filament-like structures and smaller eddies can be observed, especially at the northern part of the domain.
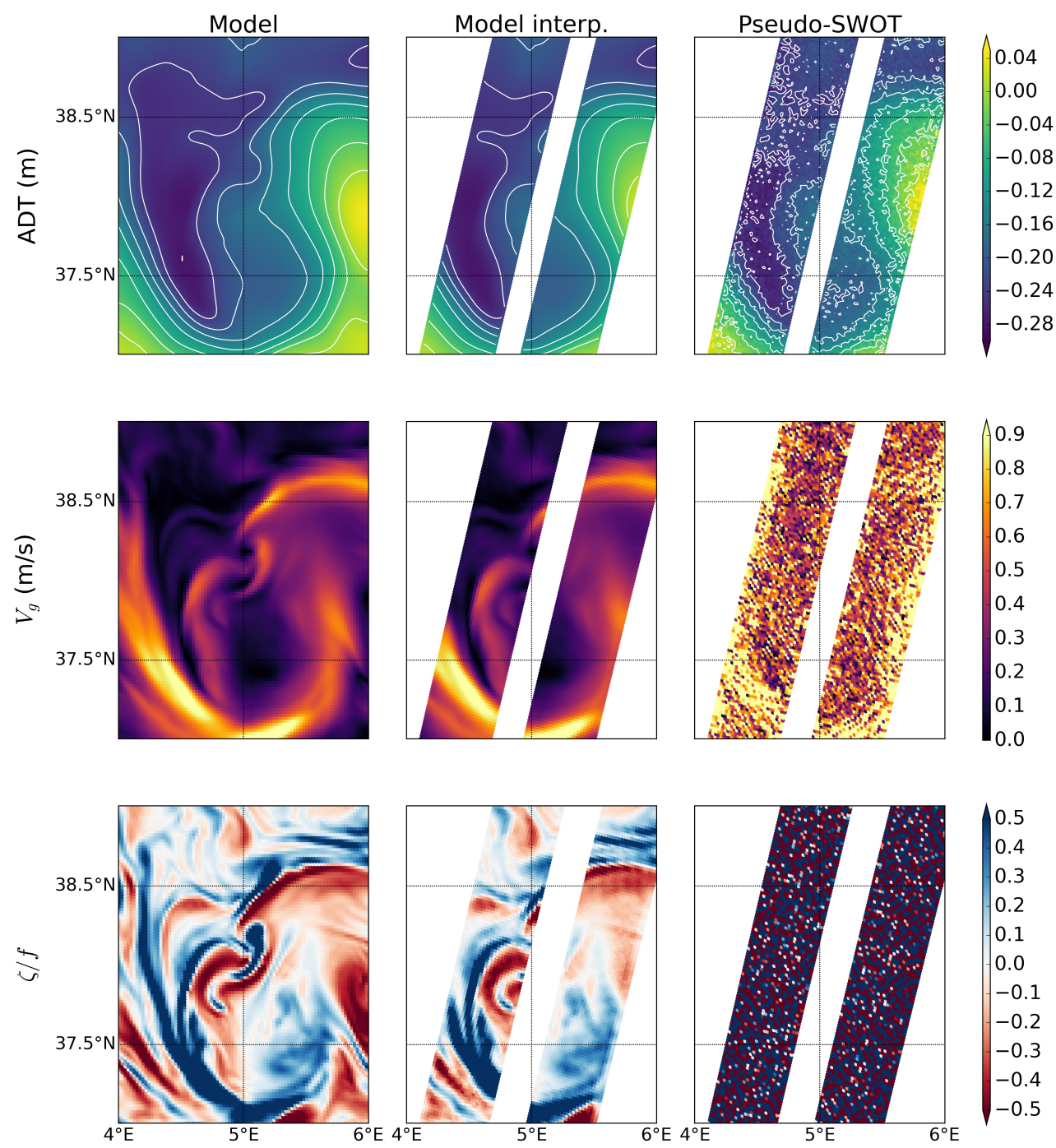

Figure 4. From top to bottom: $\mathrm{SSH}(\mathrm{m})$, geostrophic velocity $(\mathrm{m} / \mathrm{s})$ and relative vorticity $(\zeta)$ normalized by f, on 23 January 2009 corresponding to pass 15 of cycle 2 (box 1). The first, middle and last columns show the data obtained directly from the model (WMOP), from the model interpolated onto the SWOT grid $\left(\mathrm{SSH}_{\text {model }}\right)$, and with added noise $\left(\mathrm{SSH}_{o b s}\right)$, respectively. 

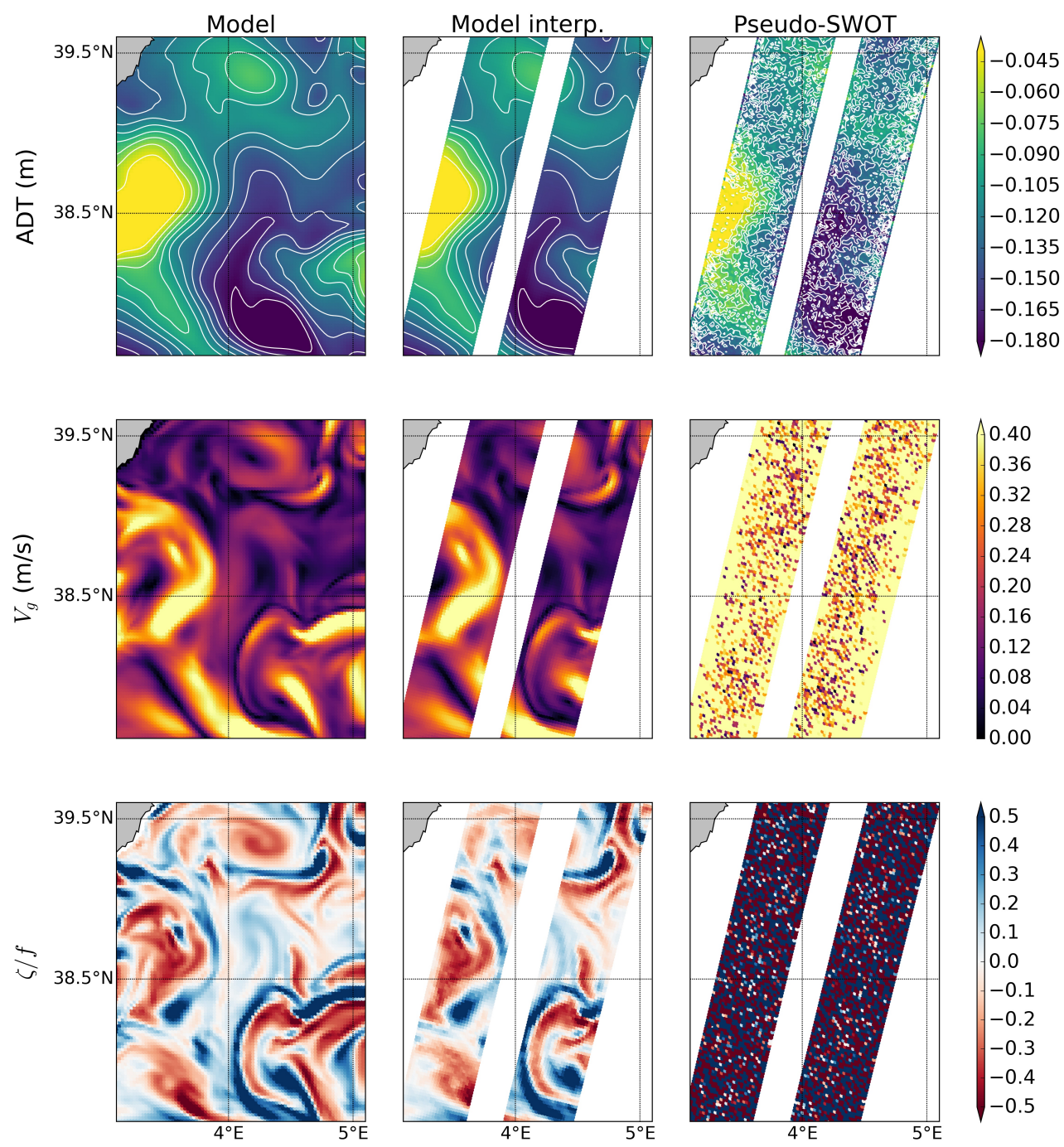

Figure 5. From top to bottom: SSH $(\mathrm{m})$, geostrophic velocity $(\mathrm{m} / \mathrm{s})$ and relative vorticity $(\zeta)$ normalized by f, on 3 February 2009 corresponding to pass 168 of cycle 2 (box 2). The first, middle and last columns show the data obtained directly from the model (WMOP), from the model interpolated onto the SWOT grid $\left(\mathrm{SSH}_{\text {model }}\right)$, and with added noise $\left(\mathrm{SSH}_{o b s}\right)$, respectively.

The effect of the filter is assessed for SSH and its derived dynamical variables: absolute geostrophic velocity and relative vorticity. These were calculated as explained in Section 2.3.1.

As observed in the first and middle columns (model and model interpolated onto SWOT grid data, respectively) of Figures 4 and 5, SSH and its derived variables reveal fine scale features, but the noise level masks the signal of these features when derived variables are obtained from pseudo-SWOT $\mathrm{SSH}$. We can also see how the effect of the noise is lower in regions with high SSH gradients. If we compare the velocity derived from pseudo-SWOT data of box 1 and 2, for box 1 , the region with high values can still be appreciated as they reach $0.9 \mathrm{~m} / \mathrm{s}$, but not for box 2 as they only reach $0.4 \mathrm{~m} / \mathrm{s}$.

To have information on the spatial scales resolved and the effect of the noise, spatial Fourier power spectra for each filter were calculated as described in Section 2.3.2. The spectra were calculated for each individual cycle, and then averaged over the 122 cycles in which both passes 15 and 168 are available (cycle 123 stops at pass 132). Figure 6 compares the spectra of model data interpolated onto the SWOT grid and the pseudo-SWOT data. The SWOT noise starts to dominate at wavelengths lower than $60 \mathrm{~km}$. In the top panel of Figure 6, the red and blue curves separate at around $60 \mathrm{~km}$ for 
both boxes. If we look at the zoom inset, we see that for pass 15 the lines separate at slightly higher wavelengths than for pass 168 .
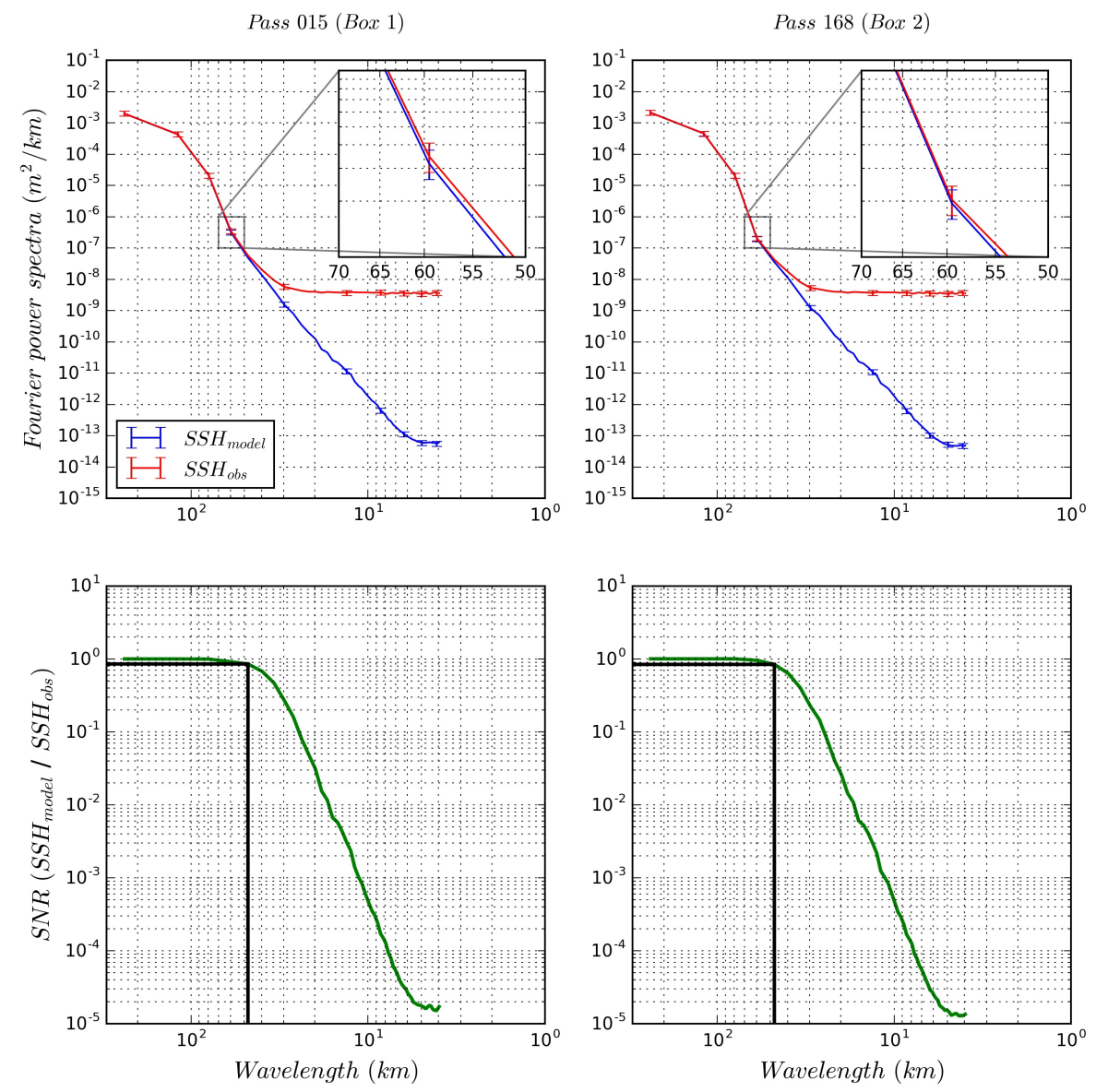

Figure 6. (Top) Spectra of the data before filtering, from cycle 1 to 122 , corresponding to box 1 (pass 15), (left), and to box 2 (pass 168), (right). Error bars denote 95\% confidence intervals. (Bottom) Corresponding Signal to Noise Ratio (SNR), with a horizontal black line indicating where the noise is more than $15 \%$ of the signal, and the vertical line the corresponding wavelength.

Nevertheless, there does not seem to be a significant difference between the mean spectra of both passes. Note also how the power spectral energy level of $\mathrm{SSH}_{o b s}$ at wavelengths lower than $20 \mathrm{~km}$ stabilizes around $3.7 \times 10^{-9}$ for both passes, whilst the energy level of $\mathrm{SSH}_{\text {model }}$ reduces until it reaches the grid scale. If we look at the signal to noise ratio (SNR), we find that below $50 \mathrm{~km}$ wavelength the energy of the noise is significant with respect to that of the signal (SNR values below $15 \mathrm{~dB}$ at wavelengths smaller than $47.6 \mathrm{~km}$, i.e., the energy of the noise accounts for more than $15 \%$ of the energy of the signal for these scales). Such low SNR values make particularly challenging the denoising issue for scales below $50 \mathrm{~km}$ [36]. Consequently, we expect that the best filter parametrization will be one corresponding to $\lambda_{\mathrm{c}}$ between 47.6 and $60 \mathrm{~km}$.

\subsection{SWOT Data Filtering}

The Laplacian diffusion filter was applied to remove the noise and, thus, reduce the difference between the spectrum obtained from SWOT estimates with and without noise (Figure 6). Given the results obtained from the non-filtered data spectra, $\lambda_{\mathrm{c}}$ is first chosen to be $60 \mathrm{~km}$. We then choose smaller $\lambda_{\mathrm{c}} \mathcal{S}(50,40,30$ and $15 \mathrm{~km})$ to see how much lower we can go with this filter. We go down to $15 \mathrm{~km}$, which is the expected wavelength at which SWOT will measure SSH. For comparison, we also 
choose $\lambda_{\mathrm{c}}=200 \mathrm{~km}$, which is the wavelength resolved by present-day altimeter constellation fields [11]. We lastly choose $\lambda_{\mathrm{c}}=100 \mathrm{~km}$ as an intermediate value between 60 and $200 \mathrm{~km}$.

In Figures 7 and 8, we show the effect of the filter on SSH at different values of $\lambda_{\mathrm{c}}$ s. For Figure 7 , the effect of the filter is mainly seen in the pseudo-SWOT data, especially in the northern part where smaller structures are present. In Figure 8, as there are more, smaller structures, we can see more differences between the filtered outputs with respect to the model interpolated and pseudo-SWOT data. These differences are not only in the shape of the structures that are present, but also in their intensity. On the top row of Figures 7 and 8, the original model is also included to show that differences do also arise from the interpolation onto the SWOT grid. In Figure 7, especially for the $200 \mathrm{~km} \lambda_{\mathrm{c}}$, we can observe that the original structure present is significantly altered. This emphasizes the importance for development of interpolation techniques to fill the gap between the two swaths with the help of the nadir altimeter data. In Figures 7 and 8, the SSH images for the different filters look very similar, but the differences are amplified when the first derivatives (Figures 9 and 10) and second derivatives (Figures 11 and 12) are calculated.

After applying the Laplacian diffusion filter, we can now retrieve the structures present in the pseudo-SWOT SSH in the absolute geostrophic velocity plots (Figures 9 and 10). With a $15 \mathrm{~km} \lambda_{\mathrm{c}}$ filter, the effect of the noise can be still clearly observed, especially for box 2 where smaller structures are present. As a result, although the main structures are recovered after filtering, their shapes are not accurately retrieved. Even if spurious structures remain, with a $30 \mathrm{~km} \lambda_{\mathrm{c}}$ there is a large improvement with respect to the $15 \mathrm{~km} \lambda_{\mathrm{c}}$. This improvement seems greater for box 1 than box 2 , as the noise seems to have a greater effect within box 2 than box 1 . For a $40 \mathrm{~km} \lambda_{\mathrm{c}}$, in box 1 , we can no longer qualitatively see any remaining noise, but we can see some in box 2 . For $\lambda_{\mathrm{c}} s$ greater than or equal to $50 \mathrm{~km}$, the effect of the noise is no longer observed in either box 1 (Figure 9) or box 2 (Figure 10). On the other hand, we observe a large decrease of the magnitude of the velocities from the 15 to the $200 \mathrm{~km} \lambda_{\mathrm{c}}$. With this filtering method, the intensity of the structures present, and thus the signal, decreases with the increase of $\lambda_{\mathrm{c}}$.

In the relative vorticity plots, the loss of signal with the increase of $\lambda_{c}$ is even more evident. With no filtering, the relative vorticity of box 1 ranges from $-1.82 \mathrm{f}$ to $1.66 \mathrm{f}$ for $\mathrm{SSH}_{\text {model }}$ and from $-15.22 \mathrm{f}$ to $18.16 \mathrm{f}$ for $\mathrm{SSH}_{o b s}$ (Figure 4). With a $200 \mathrm{~km} \lambda_{\mathrm{c}}$, this reduces to $-0.23 \mathrm{f}$ to $0.14 \mathrm{f}$ for both $\mathrm{SSH}_{\text {model }}$ and $\mathrm{SSH}_{o b s}$ (Figure 11). For box 2, with no filtering, the relative vorticity ranges from $-0.71 \mathrm{f}$ to $1.50 \mathrm{f}$ for $\mathrm{SSH}_{\text {model }}$ and from $-17.39 \mathrm{f}$ to $17.71 \mathrm{f}$ for $\mathrm{SSH}_{o b s}$ (Figure 5). For $200 \mathrm{~km}$, it reduces to $-0.07 \mathrm{f}$ to $0.10 \mathrm{f}$ for $\mathrm{SSH}_{\text {model }}$ and from $-0.09 \mathrm{f}$ to $0.06 \mathrm{f}_{\text {for }} \mathrm{SSH}_{o b s}$ (Figure 12). There is approximately two orders of magnitude difference between the vorticity calculated from the original data, and that filtered at $\lambda_{\mathrm{c}}=200 \mathrm{~km}$. For box 1, the velocity appears to contain no further noise with $\lambda_{\mathrm{c}}=40 \mathrm{~km}$, but this filtering is not sufficient to properly reconstruct the relative vorticity. With a $50 \mathrm{~km} \lambda_{\mathrm{c}}$, some noise is still present, and with $60 \mathrm{~km} \lambda_{\mathrm{c}}$, there appears to be no remaining noise. For box 2, the velocity appears to have no further noise with a $50 \mathrm{~km} \lambda_{\mathrm{c}}$, and, similarly to box 1, we use a $60 \mathrm{~km} \lambda_{\mathrm{c}}$ to qualitatively remove remaining noise in the relative vorticity plots. The relative vorticity fields present unrealistic small-scale structures at larger $\lambda_{\mathrm{c}} \mathcal{S}$ values than SSH and velocity. This is expected as the noise effects increase as higher order derivatives are reached. Nevertheless, the larger structures present in the images are recovered from the non-filtered image with a $60 \mathrm{~km} \lambda_{\mathrm{c}}$ filter for both box 1 and 2. Not as much signal is lost with a 60 as with a $200 \mathrm{~km} \lambda_{\mathrm{c}}$, but some is still lost. For the mesoscale, given the relative vorticity and structures observed in Figures 11 and 12, this does not seem to have a large impact. However, there may be an impact when wanting to observe finer scales as we retrieve normalized relative vorticity much lower than 1 .

Spectra were computed for $\lambda_{\mathrm{c}} s$ of 30,60 and $200 \mathrm{~km}$ to visualize these effects. The corresponding SNR is also calculated in two different ways by using two references. One is by dividing the filtered model-interpolated data by the filtered pseudo-SWOT data, and the other by dividing the non-filtered model-interpolated data by the filtered pseudo-SWOT data. This is shown in Figures 13 and 14. 

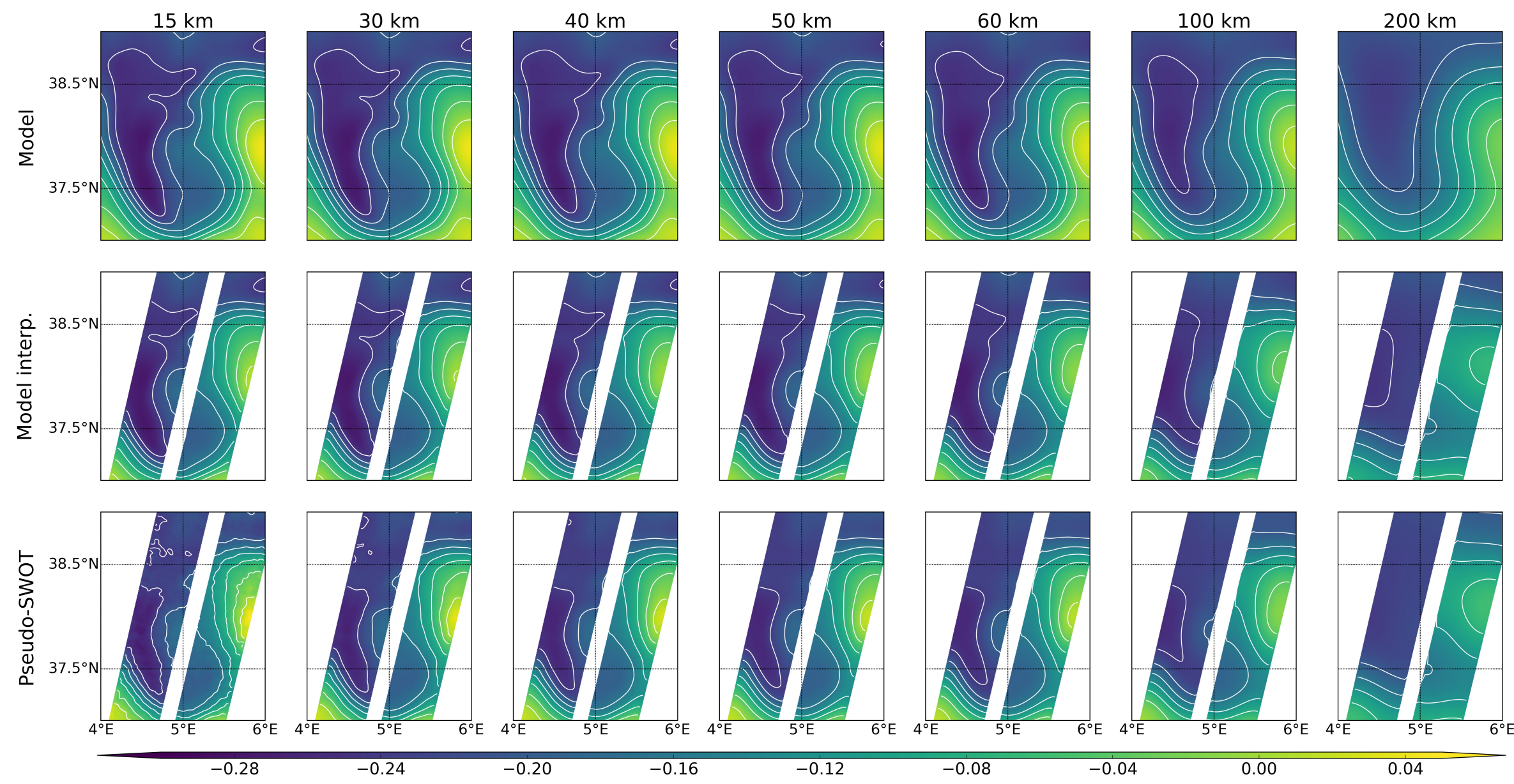

Figure 7. SSH (m) on 23 January 2009 corresponding to pass 15 of cycle 2. 

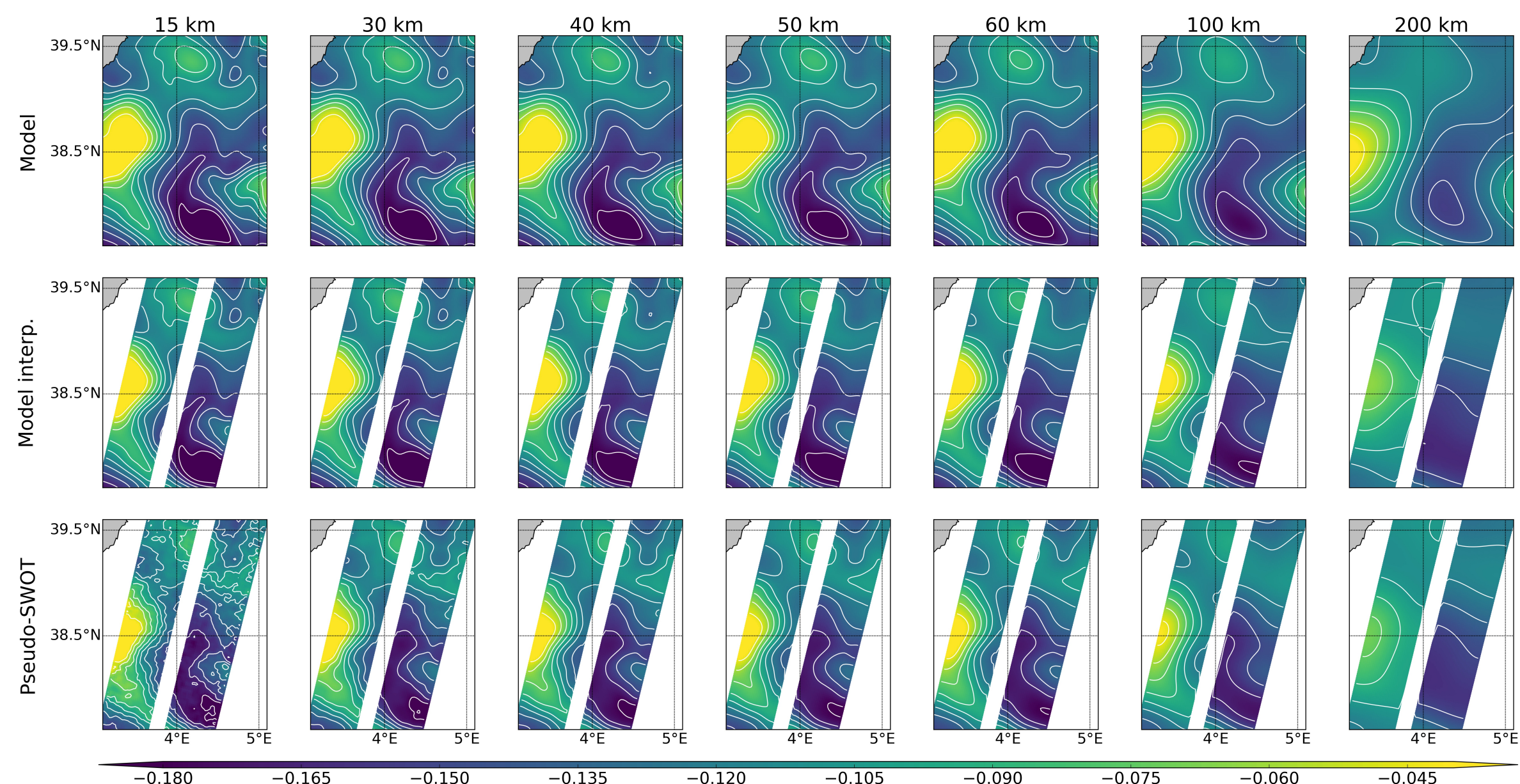

Figure 8. SSH (m) on 3 February 2009 corresponding to pass 168 of cycle 2. 

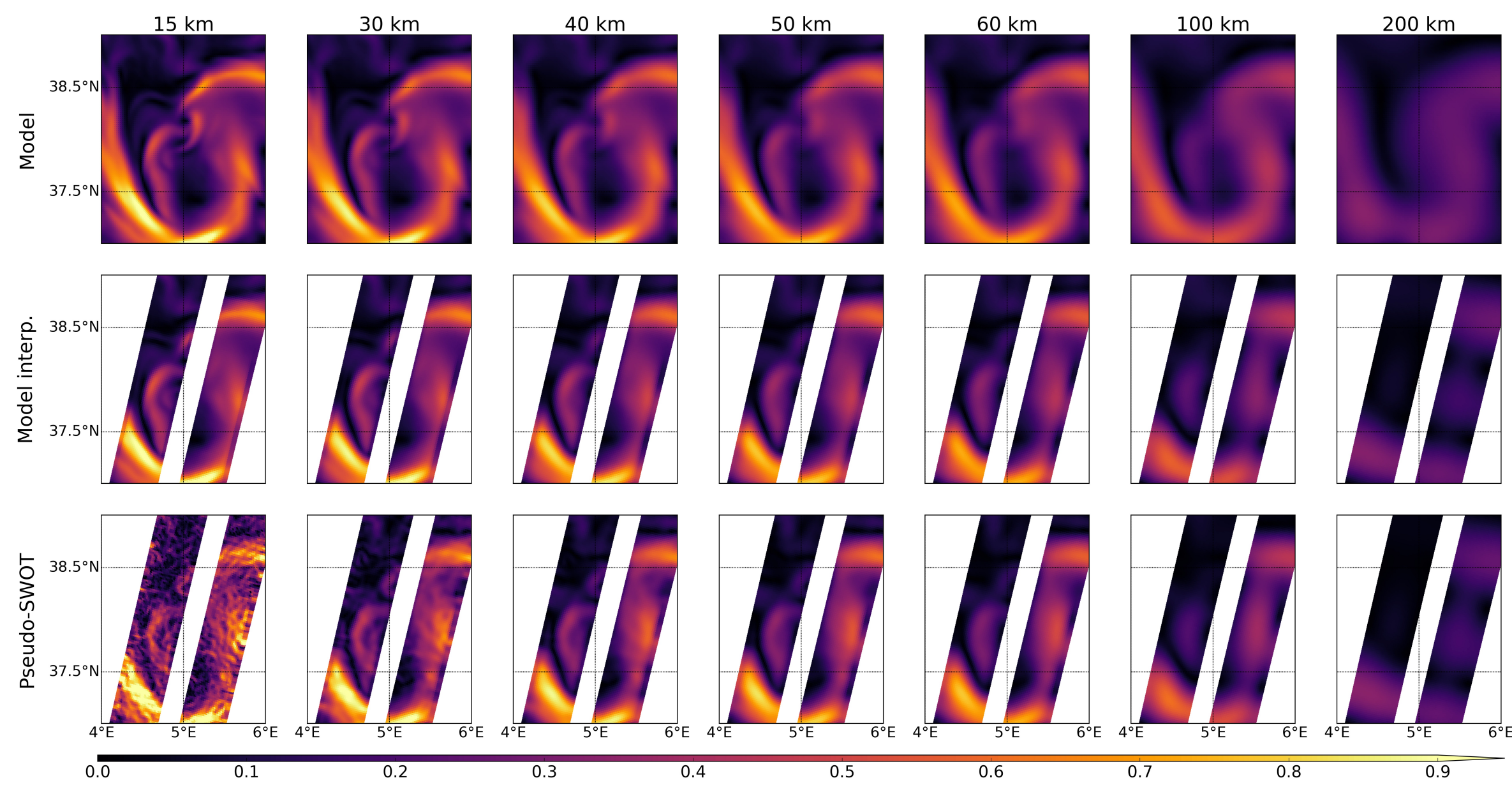

Figure 9. Absolute geostrophic velocity (m/s) on 23 January 2009 corresponding to pass 15 of cycle 2 . 

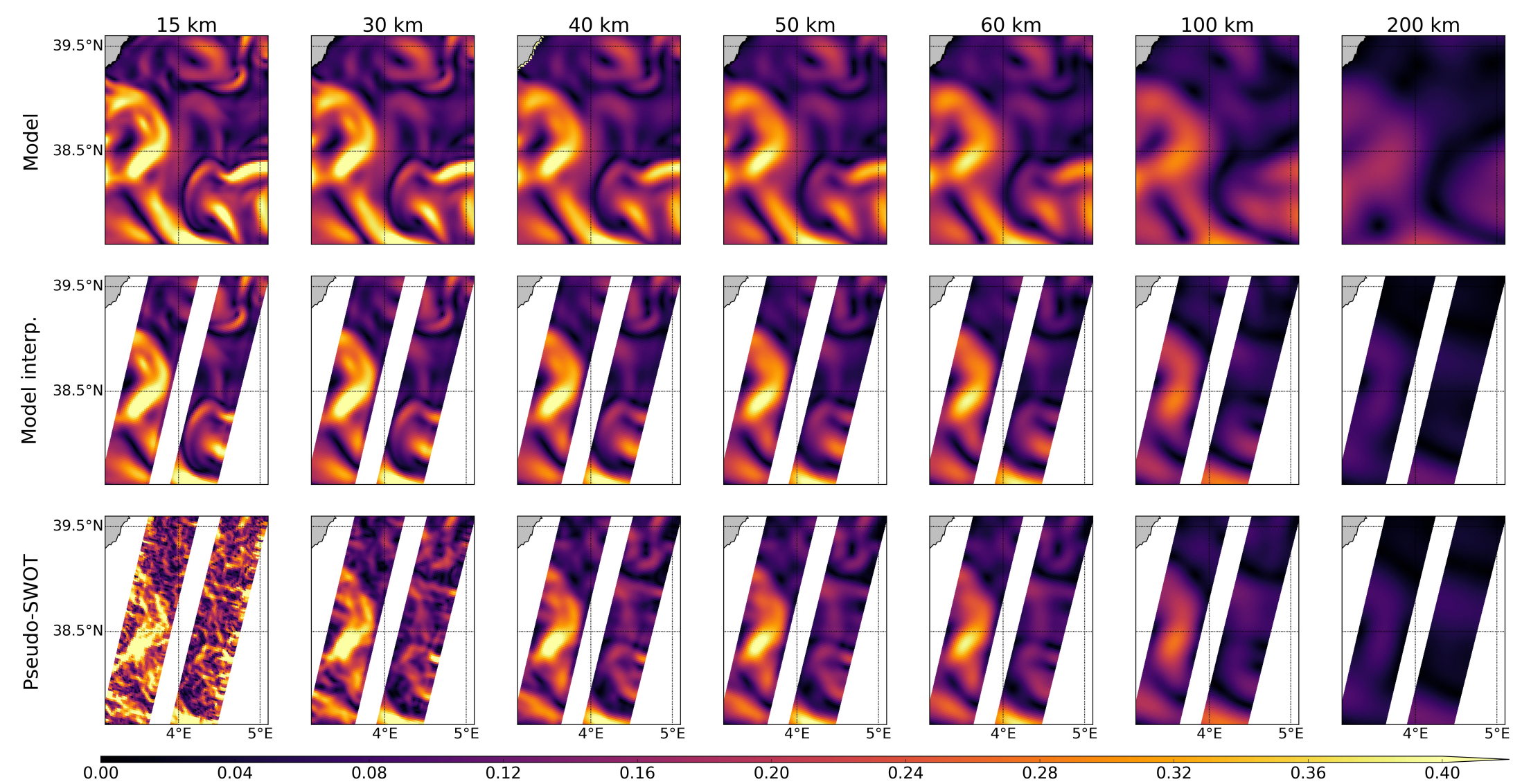

Figure 10. Absolute geostrophic velocity (m/s) on 3 February 2009 corresponding to pass 168 of cycle 2. 

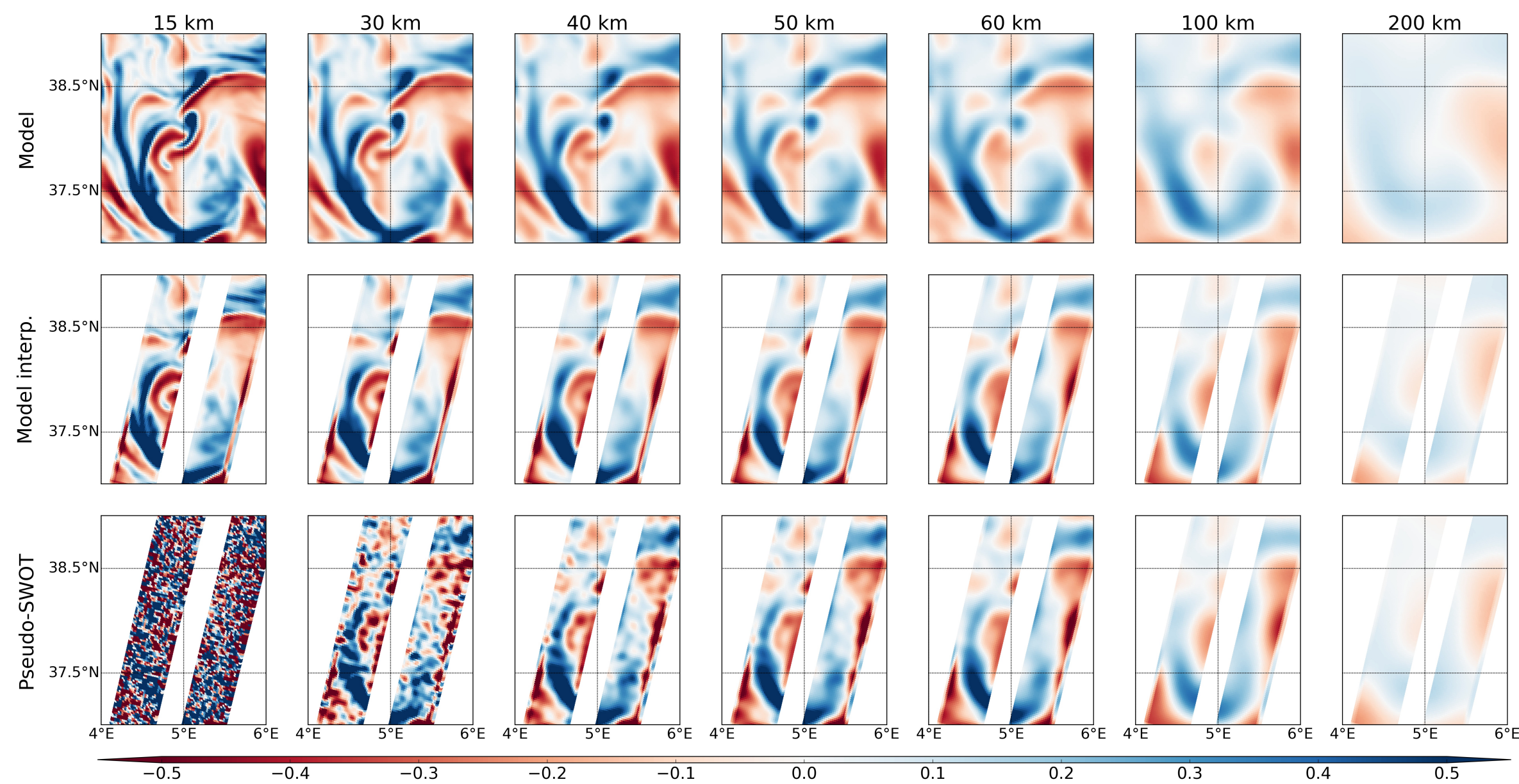

Figure 11. Relative vorticity normalized by f on 23 January 2009 corresponding to pass 15 of cycle 2 . 

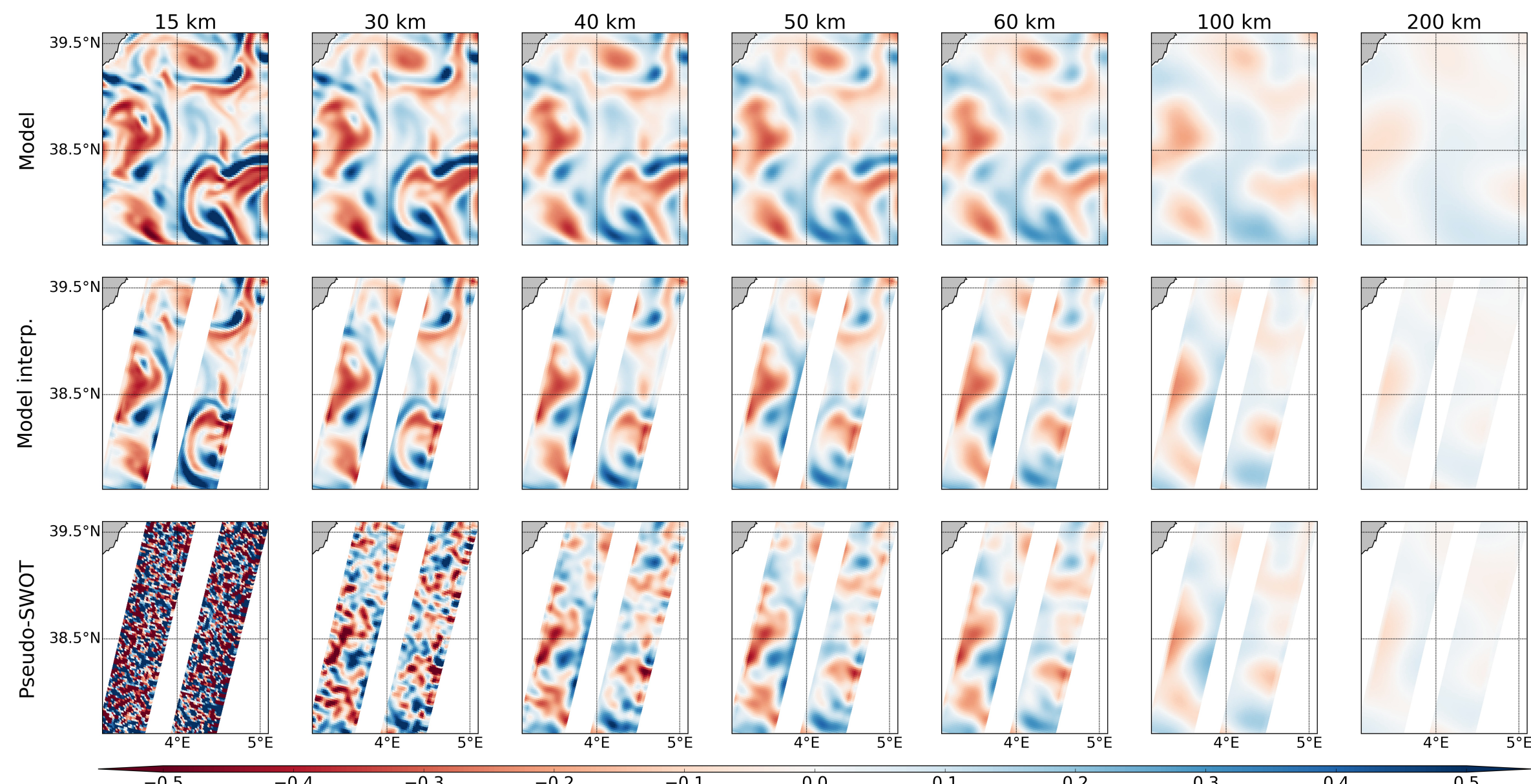

Figure 12. Relative vorticity normalized by f on 3 February 2009 corresponding to pass 168 of cycle 2 
$30 \mathrm{~km}$
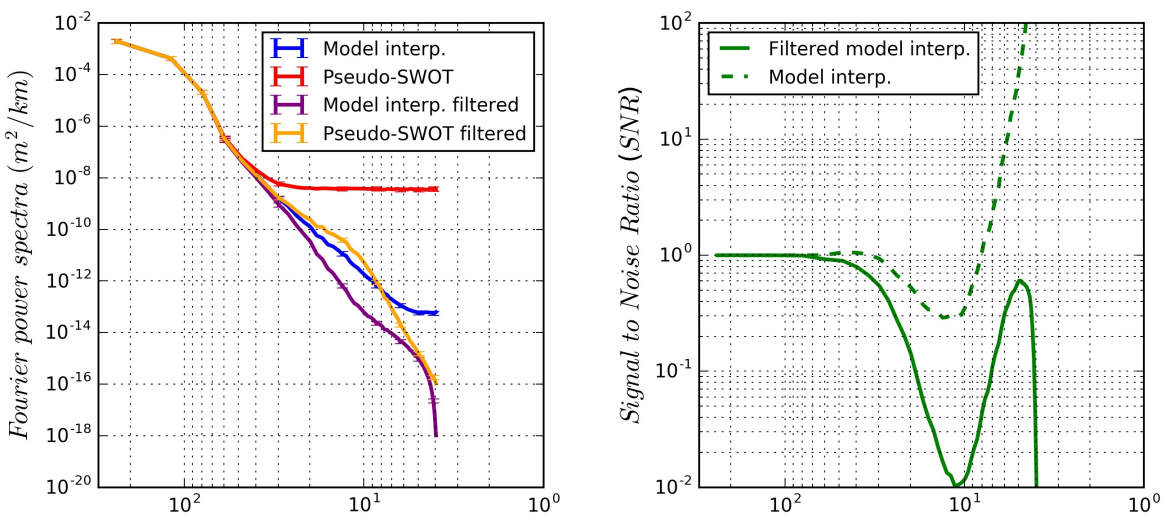

$60 \mathrm{~km}$
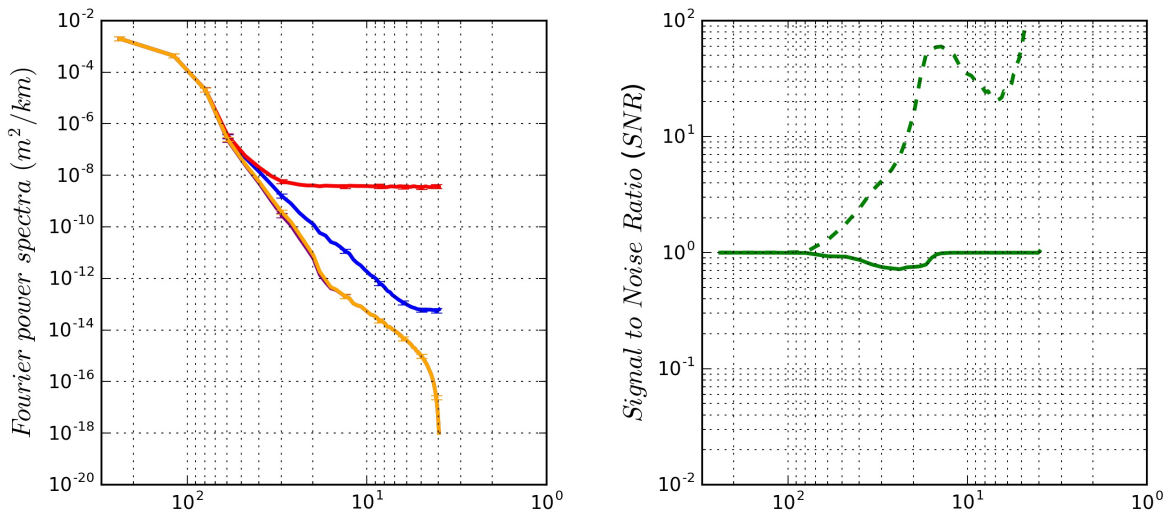

$200 \mathrm{~km}$
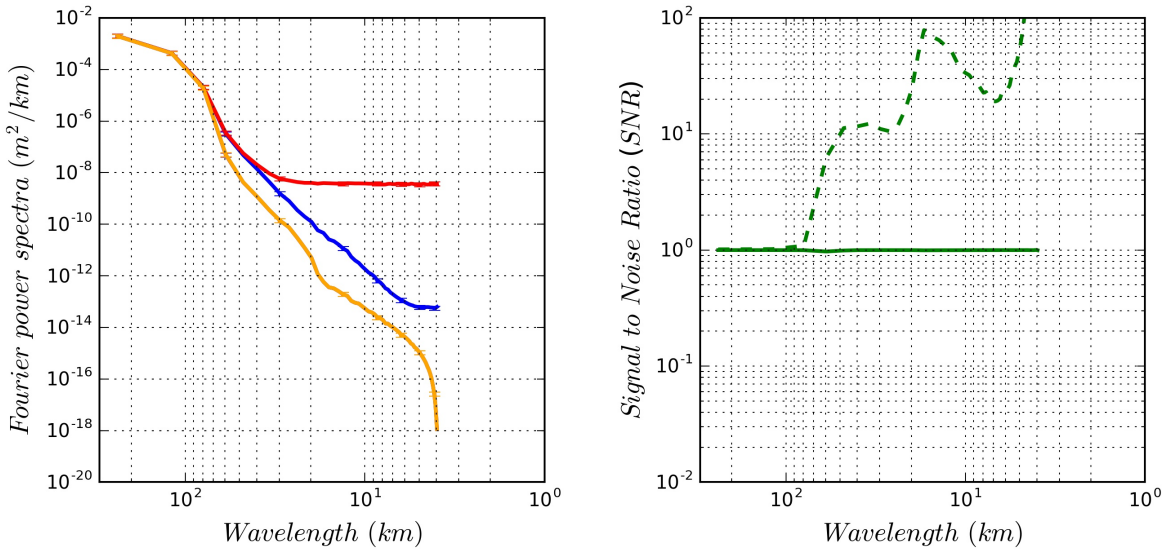

Figure 13. Box 1 region (pass 15) mean of cycles 1 to 122. (Left) Spectra of $\mathrm{SSH}_{\text {model }}$ (blue) and $\mathrm{SSH}_{o b s}$ (red) before filtering and after applying the different cut-off wavelengths shown in the different rows (30, 60 and $200 \mathrm{~km})$ in purple and orange, respectively. Error bars denote $95 \%$ confidence intervals. (Right) SNR of $\mathrm{SSH}_{\text {model }}$ and $\mathrm{SSH}_{o b s}$, both filtered (solid line) and of $\mathrm{SSH}_{\text {model }}$ non-filtered and filtered $\mathrm{SSH}_{o b s}$ (dashed line). 
$30 \mathrm{~km}$
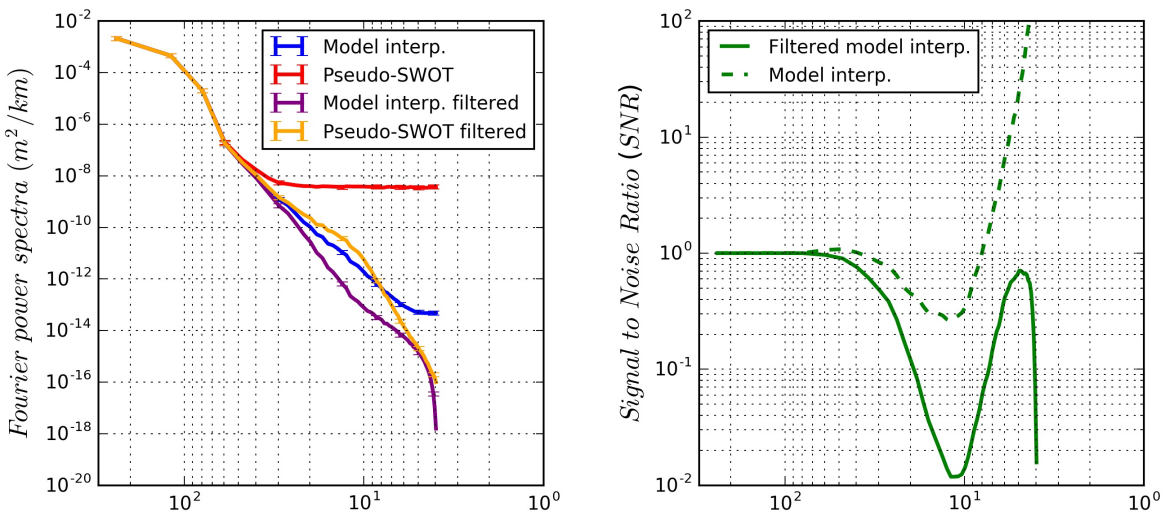

$60 \mathrm{~km}$
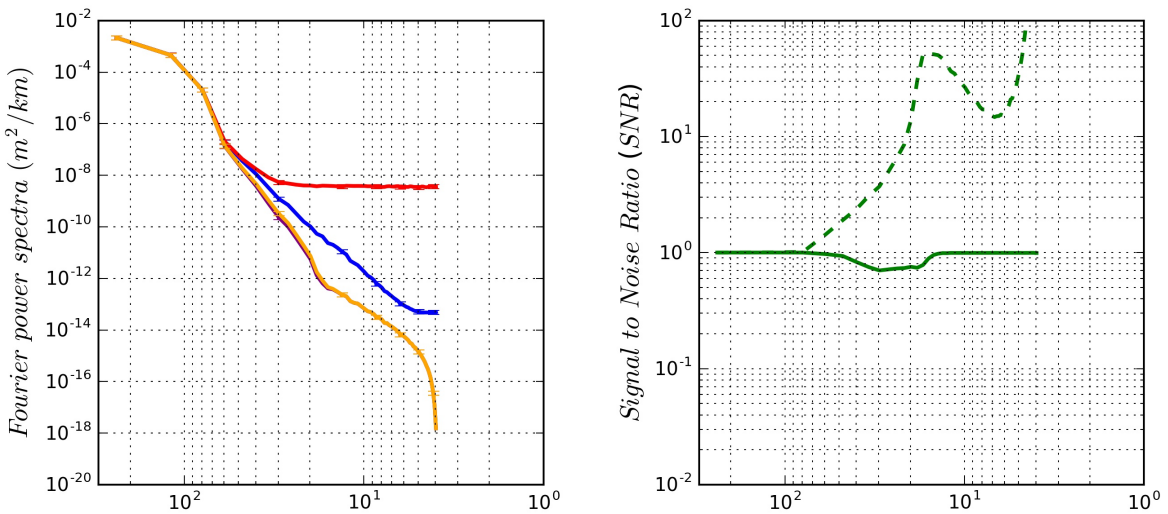

$200 \mathrm{~km}$
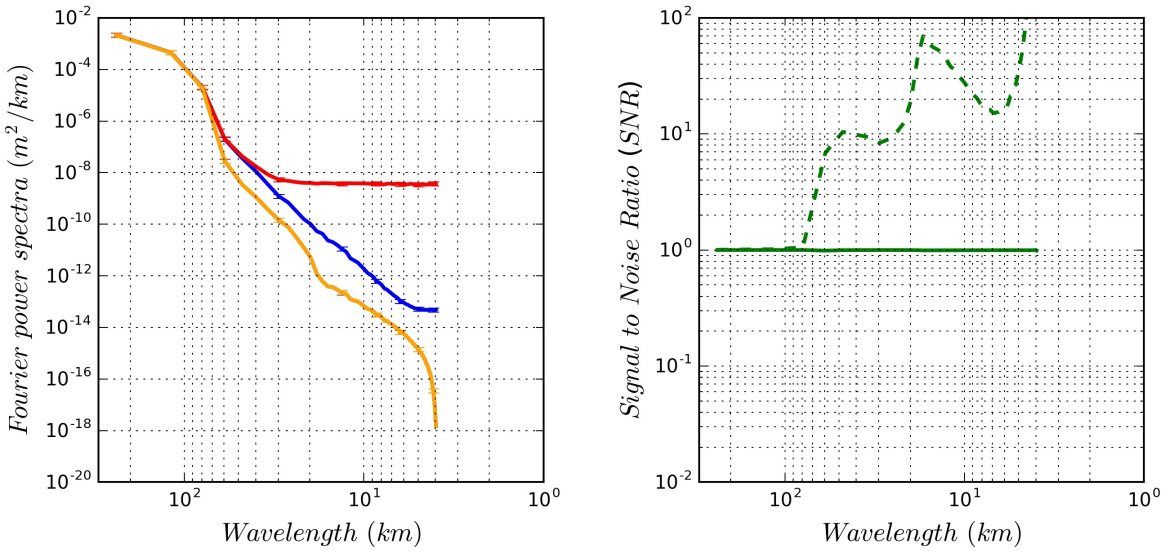

Figure 14. Box 2 region (pass 168) mean of cycles 1 to 122. (Left) Spectra of $\mathrm{SSH}_{\text {model }}$ (blue) and $\mathrm{SSH}_{o b s}$ (red) before filtering and after applying the different cut-off wavelengths shown in the different rows $(30,60$ and $200 \mathrm{~km})$ in purple and orange, respectively. Error bars denote $95 \%$ confidence intervals. (Right) SNR of $\mathrm{SSH}_{\text {model }}$ and $\mathrm{SSH}_{o b s}$, both filtered (solid line) and of $\mathrm{SSH}_{\text {model }}$ non-filtered and filtered $\mathrm{SSH}_{o b s}$ (dashed line).

As a consequence of the application of the filter, the separation of the spectral curves of $\mathrm{SSH}_{\text {model }}$ (model-interp.) and $\mathrm{SSH}_{\text {obs }}$ (pseudo-SWOT) is reduced. As seen in Figure 6, with no filter, the model-interp. (blue) and pseudo-SWOT (red) curves separate at a wavelength around $60 \mathrm{~km}$. With a $30 \mathrm{~km} \lambda_{\mathrm{c}}$, the noise level is still high, as observed in Figures 7-12, but the power spectra difference at wavelengths smaller than $60 \mathrm{~km}$ between the pseudo-SWOT filtered (yellow) and the model-interp. 
(blue) curves is much smaller than it is between the model-interp (blue) and pseudo-SWOT (red) curves (top left panel of Figures 13 and 14). Moreover, the pseudo-SWOT filtered and the model-interp. curves separate at smaller wavelengths. If we look at the dashed line of the top right panel of Figures 13 and 14, we can more accurately determine this wavelength separation value by looking at where the dashed curve starts decreasing. This corresponds to 30 and $40 \mathrm{~km}$ wavelengths for box 1 and 2, respectively. Between wavelengths of 60 and $30 \mathrm{~km}$ (40 for box 2), the SNR (dashed line) is greater than 1, indicating some over-filtering/smoothing, but this value is very low (1.064 for box 1 and 1.088 for box 2). The pattern of the SNR of the filtered model-interp. over the filtered pseudo-SWOT data (solid line of top right panel of Figures 13 and 14) is similar to that of Figure 6. The noise gains importance as the wavelengths reduce from $60 \mathrm{~km}$, but the SNR values of the $30 \mathrm{~km}$ $\lambda_{\mathrm{c}}$ are lower than the non-filtered ones. On the other hand, this indicates that, given that the filtered model-interp. and pseudo-SWOT spectra are still quite different, a larger $\lambda_{\mathrm{c}}$ is necessary. In both the left and right panels of the $30 \mathrm{~km} \lambda_{\mathrm{c}}$ of Figures 13 and 14, anomalous patterns are observed below the $10 \mathrm{~km}$ wavelength. Not only are these spatial scales very small, but, if we look at the spectra values, they are about $10^{-12} \mathrm{~m}^{2} / \mathrm{km}$ or lower. We consider these values to be too low for discussion.

With a $60 \mathrm{~km} \lambda_{\mathrm{c}}$, the noise is further reduced, but we lose more signal too. If we look at the continuous line of the right panel of Figures 13 and 14, we see that it remains approximately constant at 1 . For box 1 , it reaches a minimum SNR of 0.715 and for box 2 of 0.697 . Looking at the dashed line, the SNR becomes larger than 1 at wavelengths lower than $80 \mathrm{~km}$ for both boxes. This means that, although we eliminate all the noise, we are also eliminating part of the signal that was initially present. At wavelengths greater than $10 \mathrm{~km}$, the power spectra of the filtered pseudo-SWOT reach a maximum difference nearly two orders of magnitude smaller than the original model-interp. spectra.

Lastly, with a $200 \mathrm{~km} \lambda_{\mathrm{c}}$ filtering, the model-interp. and pseudo-SWOT spectra curves are identical, and the SNR (solid line) is approximately 1 (Figures 13 and 14, bottom row): however, as observed in Figures 7-12, we lose a lot of signal. In the 20-80 km wavelength range, we can see how the SNR curves (dashed line) rapidly increase and the values are greater with a $200 \mathrm{~km} \lambda_{\mathrm{c}}$ than with a $60 \mathrm{~km}$ $\lambda_{c}$. At wavelengths lower than $80 \mathrm{~km}$, on average, there is about one order of magnitude difference between the filtered spectra and the original $\mathrm{SSH}_{\text {model }}$. It is also interesting to note that the purple and yellow curves separate from the red and blue at $80 \mathrm{~km}$ instead of 60 , showing that this cut-off exceeds that necessary to remove the noise. This also emphasizes how with SWOT a major advancement could be made as lower cut-off wavelengths will be possible, and thus the observation of smaller scale structures than with contemporary satellites. On the one hand, this result is expected thanks to the 2D swath instead of only 1D nadir data, but, on the other hand, it is important to remember that these are simulated from expected errors and that not all errors are implemented (see Appendix B).

To further quantify the differences observed between the different $\lambda_{\mathrm{c}} s$ in Figures 7-12, the RMSE between the interpolated model and pseudo-SWOT data shown in these Figures were calculated as described in Section 2.3.3.

In Figure 15, it is interesting to focus on the minimum points of the RMSE curves. Looking at the $\lambda_{\mathrm{c}}$ corresponding to the different minimum points, for both boxes, the minimum of the curve for SSH and the absolute geostrophic velocity $(\mathrm{Vg})$ is found for a $30 \mathrm{~km}(29) \lambda_{\mathrm{c}}$. It is slightly higher, $40 \mathrm{~km}$ (41), for relative vorticity. This directly relates to the amplification of fine scale structures, and thus the effect of the noise, in the computation of second-order derivatives. It is also in accordance with what is found in the SNR in Figure 6, which shows that we cannot recover the signal at wavelengths lower than 40-50 km. With the qualitative (Figures 7-12) and the spectra (Figures 13 and 14) plots, we saw that, for box 2 , as the signal is lower than in box 1 , the effect of the noise is greater, and larger $\lambda_{\mathrm{c}} s$ are necessary. The RMSE plots show us another point of view. As the signal is not as intense in box 2 as in box 1, the over-smoothing (signal lost) due to the Laplacian diffusion filter is lower, and thus we observe lower RMSE values in Figure 15. Moreover, the improvement of the RMSE values is greater for box 2 than box 1. For SSH, the RMSE reduces by 0.05 and $0.07 \mathrm{~m}$ from the no filter $\left(0 \lambda_{\mathrm{c}}\right)$ to the 
minimum RMSE, for box 1 and box 2, respectively. For $\mathrm{Vg}$, the RMSE reduces by 0.42 and $0.455 \mathrm{~m} / \mathrm{s}$, and for $\zeta / \mathrm{f}$ by 3.2 and 3.35 .
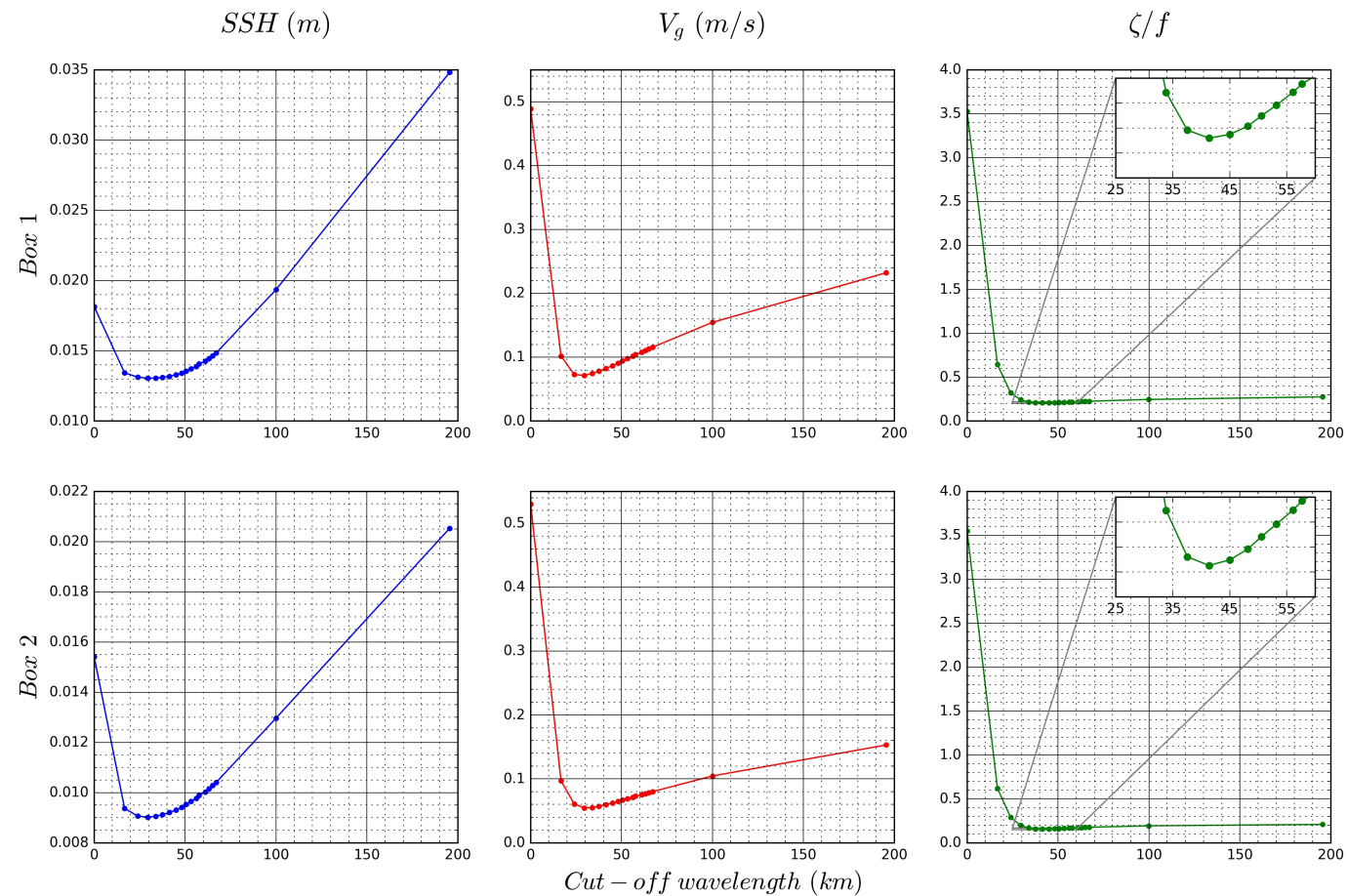

Figure 15. RMSEs of the different variables against the filter's cut-off wavelengths applied to SSH, for pass 15 (top) and pass 168 (bottom) of cycle 2. Insets show zoom of marked region for better observation of the curves' minimum points.

For SSH, we could say that with a $40 \mathrm{~km} \lambda_{\mathrm{c}}$ it is sufficient, but if we do not want to see the effect of the noise in vorticity, we need a greater $\lambda_{c}$ of $60 \mathrm{~km}$. Therefore, together with what is observed in Figures 4-15, we consider that, with this filtering technique applied to this region, SWOT will be able to resolve wavelengths down to a $40-60 \mathrm{~km}$ wavelength range. This is the $\lambda_{\mathrm{c}}$ range where we found that there is a compromise between filtering out the noise of SSH and its derived variables ( $\mathrm{Vg}$ and $\zeta / \mathrm{f}$ ), and over-smoothing the original image as little as possible. It is important to note that $\lambda_{\mathrm{c}}$ depends on the signal-to-noise ratio between SSH signals and instrument noise at fine scales. As such, it can be expected to change from region to region (and from season to season) depending on the energy levels at fine scales and on the noise level.

\section{Discussion}

We find that, by applying our filtering technique to pseudo-SWOT data in the western Mediterranean region, we cannot reach the $15 \mathrm{~km}$ wavelength argued for by [12]. We are however able to recover the signal within a swath down to wavelengths of $40-60 \mathrm{~km}$. This wavelength range is close to the one found by [10] at the western boundary currents and nearly half the wavelength values found at the eastern basins by 1D altimeter data. In addition, with the characteristic of SWOT providing 2D SSH data, this will imply a large improvement on the $200 \mathrm{~km}$ wavelength resolved by present-day gridded altimetric fields [11]. The SWOT resolved wavelengths found will make it possible to detect structures of 20-30 km in diameter (following [37]) and therefore opens the possibility for observation of fine scales that are unobservable by contemporary altimetric products. This filter is a useful tool for studies comparing the capacities of pseudo-SWOT data with the present altimetric satellite constellation data. As this filter is particularly effective in removing the spatially uncorrelated 
KaRIn noise, it may allow the application of already developed techniques that more effectively remove other correlated errors [38].

We find that the presence of structures of different scales and regimes governing-for example, the mesoscale (Ro. order(0.1)) or submesoscale (Ro. order(1)) affects our results on the efficiency of the Laplacian diffusion filter. This filter is therefore sensitive to the presence of different patterns, depending on the region. To reach even smaller scales, it is important to use filtering techniques that conserve and/or retrieve the gradients and, thus, the intensity of the signal present in the observed field. Nonetheless, this sensitivity of the Laplacian diffusion filter could also be due to the effects of noise, depending on the structure in question and its intensity. We also note that the differences between box 1 and 2 found in, for example, the qualitative plots (Figures 7-12) and the minimum RMSE values were not very large; this is not surprising when considering how close in time the two snapshots are.

With this improvement of individual swaths, gridded and possibly daily SWOT SSH maps could be obtained through different interpolation and/or reconstruction techniques. Current gridded altimetric products are obtained using optimal interpolation (OI) [39]. OI may not be the best interpolation method. OI exploits a covariance model of the field to be interpolated. The specification of this covariance model typically relies on a trade-off between the space-time size of the missing data areas and the space-time scales of interest. A covariance model with a large correlation length may lead to an over-smoothing of fine-scale structures, whereas shorter correlation lengths result in filling large missing areas with the background field. From a computational point of view, OI requires a matrix inversion, whose complexity evolves as the cube of the number of observation points. The image-like structure of SWOT data may then be highly computationally-demanding when considering large correlation lengths to fill in large missing areas. Multi-scale OI may be an alternative. However, we expect dynamical interpolation and other data assimilation methods [40-42] to be more adapted both in terms of computational complexity and in their ability to embed relevant dynamic priors to reconstruct horizontal scales down to a few tens of kilometres from SWOT data. On the other hand, SWOT data will greatly improve the present-day OI altimetric products [5]. In addition, SWOT gridded data could be improved in the $40-60 \mathrm{~km}$ wavelength range by combining it with the data of a higher temporal resolution.

Dynamic interpolation is an example of a technique that has been investigated by [40] that could help to obtain gridded, daily SSH maps from SWOT. When they apply this method to the Gulf Stream region, they recover the SSH field down to $80 \mathrm{~km}$ wavelength. Data-driven schemes recently introduced by [41,42] are also of interest to better reconstruct horizontal scales below $100 \mathrm{~km}$. Overall, for such approaches, it is important to recover the lowest wavelengths possible as spatial resolution loss is likely when producing the gridded maps. Moreover, this spatial resolution loss might be even higher when addressing gridded maps of derived variables. Therefore, the cut-off wavelength should be adjusted to the variables that are to be studied.

Another reconstruction technique that has been investigated in the context of SWOT is a 3D multivariate reconstruction of ocean state. Ref. [43] do this by combining information from SSH and high resolution image structure observations. Once this is achieved, study of the capacity of SWOT to detect fine scale structures could be improved by, for example, better characterizing eddies. As the dataset would be of a higher spatial and temporal resolution than the L2 product, it would then be possible to apply eddy-tracking algorithms like the py-eddy tracker [44] or the code developed by [45], which have already been implemented in this region to characterize the western Mediterranean eddy field. A comparison could then be made with the eddies characterized in data from the WMOP model, in the presently available altimetric data and in pseudo-SWOT data.

In future work, the effect of the inter- and intra-annual (or seasonal) variability in the region on the results obtained could be studied too. Although mean spectra were obtained, we focused on two dates in winter. Refs. [46,47] found that there is a strong winter-summer difference in the upper ocean dynamics due to the change of stratification, with the mixed layer depth being deeper in winter. 
For example, the reconstruction of mesoscale structures in the upper ocean from pseudo-SWOT data in the Kuroshio Extension region has been studied. They found that the simulated and reconstructed vorticity correlation coefficients varied both inter- and intra-annually [48].

The implementation of filtering techniques that take into account the first and second order SSH derivatives has been started. With this, we hope that in future studies we will be able to recover even smaller wavelengths and to conserve the intensity of the signal after having applied the filter.

New versions of the SWOT simulator will allow the simulation of pseudo-SWOT data during the fast-sampling phase. This makes it possible to start preparing for the calibration/validation phase including the comparison with high resolution in situ data collected during future intensive multi-platform experiments in the western Mediterranean Sea. On the other hand, the only source of geophysical error implemented in the SWOT simulator is still just that related to the wet troposphere. New releases of the SWOT simulator may include the effects of sea state and internal tides [49]. Internal tides and waves are important sources of geophysical errors because, at wavelengths shorter than $50 \mathrm{~km}$, they can affect SWOT data [2]. Therefore, in future work, it would also be interesting to compare our results with an updated version of the SWOT simulator and other OGCMs, especially those that include tides.

\section{Conclusions}

We have generated simulated pseudo-SWOT data for the western Mediterranean Sea using a SWOT simulator and outputs from an ocean numerical model. To evaluate the output SWOT data, we derived absolute geostrophic velocities and relative vorticities from the pseudo-SWOT SSH data. We find that, due to the satellite's instrumental noise and geophysical errors, the features observed in the pseudo-SWOT SSH are lost in the derived dynamical variables. Looking at the spatial spectra, we find that noise dominates the signal at wavelengths smaller than $60 \mathrm{~km}$. We applied a Laplacian diffusion filtering technique to attempt to remove the noise and hence observe finer scales. We estimated the appropriate cut-off wavelength for each parametrization. To filter out the noise, we applied a series of ascending cut-off wavelengths: 15, 30, 40, 50, 60, 100 and $200 \mathrm{~km}$. We find that in this study region, using this technique, we cannot resolve the expected $15 \mathrm{~km}$ wavelength. On the other hand, we are able to recover the signal within a swath down to a 40-60 km wavelength range. This is still an improvement in comparison to wavelengths resolved by present-day 1D altimeters, especially at eastern basins. Robust swath-filtering is an important first step towards meeting our goals for reconstruction techniques that will enable us to combine SWOT and altimetric data in order to produce gridded SSH maps of significantly higher resolution than contemporary products. New versions of the SWOT simulator code include improved representation of instrumental and geophysical errors, and also give us the option to obtain pseudo-data for the SWOT fast-sampling phase. New pseudo-SWOT data will allow us to better refine the results of this study and to examine a wider range of scenarios.

Acknowledgments: The research leading these results has received funding from the Sea Level Thematic Assembly Center (SL-TAC) of the Copernicus Marine and Environment Monitoring Service (CMEMS) and from the Centre National d'Études Spatiales (CNES) through Ocean Surface Topography Science Team (OST/ST) project MANATEE. L. Gómez-Navarro acknowledges CNES and FP-7 PhD funding. This work was supported by a Short Term Scientific Mission (STSM) grant from COST Action ES140. E. Mason was supported by the Copernicus Marine Environment Monitoring Service (CMEMS) MedSUB project. E. Cosme and J. Le Sommer are supported by the CNES through the OST/ST and the SWOT Science Team. The WMOP simulation used in this study was produced in the framework of the MEDCLIC project funded by "La Caixa" Foundation. This study is a contribution to the PRE-SWOT project (CTM2016-78607-P) funded by the Spanish Research Agency and the European Regional Development Fund (AEI/FEDER, UE). Codes and output files are available online at the project repository (https://github.com/LauraGomezNavarro/paper_Gomez-Navarro_etal_2018).

Author Contributions: Ananda Pascual and Laura Gomez-Navarro designed the study; Ronan Fablet, Ananda Pascual and Laura Gomez-Navarro designed the filtering experiments; Baptiste Mourre provided the WMOP simulation data and helped on the analysis of the model data; Laura Gomez-Navarro, Ronan Fablet, Evan Mason, Ananda Pascual, Julien Le Sommer and Emmanuel Cosme contributed to the analysis of the results; Laura Gomez-Navarro wrote the manuscript and all authors contributed to the writing. 
Conflicts of Interest: The authors declare no conflict of interest. The founding sponsors had no role in the design of the study; in the collection, analyses, or interpretation of data; in the writing of the manuscript, and in the decision to publish the results.

\section{Abbreviations}

The following abbreviations are used in this manuscript:

$\begin{array}{ll}\text { ADT } & \text { Absolute Dynamic Topography } \\ \text { AEMET } & \text { Spanish Meteorological Agency } \\ \text { CNES } & \text { Centre National d'Études Spatiales } \\ \text { HIRLAM } & \text { HIgh Resolution Limited Area Model } \\ \text { KaRIn } & \text { Ka-band Radar Interferometer } \\ \text { NASA } & \text { National Aeronautics and Space Administration } \\ \text { OGCM } & \text { Oceanic General Circulation Model } \\ \text { PDE } & \text { Partial Derivative Equation } \\ \text { RMSE } & \text { Root Mean Square Error } \\ \text { ROMS } & \text { Regional Oceanic Modeling System } \\ \text { SOCIB } & \text { the Balearic Islands Islands Coastal Observing and Forecasting System } \\ \text { SSH } & \text { Sea Surface Height } \\ \text { SNR } & \text { Signal to Noise Ratio } \\ \text { SWOT } & \text { Surface Water Ocean Topography } \\ \text { WMOP } & \text { Western Mediterranean OPerational forecasting system }\end{array}$

\section{Appendix A}

In order to know which number of iterations and lambda to set in the filter's parametrization, the filter was applied to a set of 100 randomly generated white noise fields. Spectra were then obtained and the cut-off wavelength was found by identifying the one that corresponded to where the energy was reduced to a half. An example is shown in Figure A1.

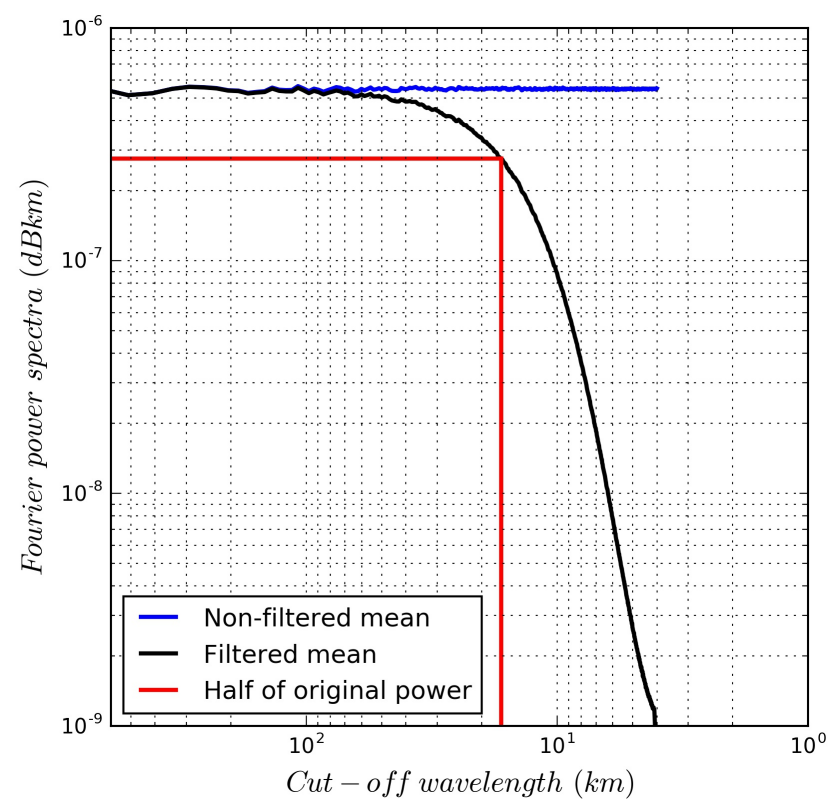

Figure A1. Illustration of how the parameterization corresponding to a 15 (16.72) km cut-off wavelength $\left(\lambda_{c}\right)$ is estimated. The blue line represents the mean spectra of the 100 non-filtered white noise fields. The black line is the mean spectra of the 100 filtered white noise fields. The horizontal red line shows the half-power spectra of the blue line, and the vertical red line the corresponding wavelength value of the black line, and thus the cut-off wavelength. 
In Table A1, we show the different $\lambda_{\mathrm{c}}$ obtained for a set of lambdas and number of iterations and in Figure A2 a plot of the values shown in Table A1 is presented. As can be observed in Table A1, in most cases, several combinations of lambdas and iterations can give the same cut-off wavelength. We decided to choose the combination corresponding to the smallest lambda, as the smaller the lambda, the smaller the over-smoothing.

Table A1. Cut-off wavelengths $\left(\lambda_{\mathrm{c}}\right)$ values and their corresponding lambda and number of iterations (iter) combinations. The cut-off wavelengths shown in Figures 7-12 are in bold.

\begin{tabular}{|c|c|c|c|c|c|c|c|c|c|c|c|}
\hline Cut-off & Lambda & Iter & Cut-off & Lambda & Iter & Cut-off & Lambda & Iter & Cut-off & Lambda & Iter \\
\hline 16.72 & 0.05 & 50 & 71.88 & 0.10 & 450 & 105.09 & 0.20 & 500 & 141.41 & 0.35 & 500 \\
\hline \multirow[t]{2}{*}{23.95} & 0.05 & 100 & & 0.15 & 300 & & 0.25 & 400 & & 0.40 & 450 \\
\hline & 0.10 & 50 & & 0.30 & 150 & & 0.30 & 350 & & 0.45 & 400 \\
\hline \multirow[t]{2}{*}{29.47} & 0.05 & 150 & & 0.45 & 100 & & 0.35 & 300 & & 0.50 & 350 \\
\hline & 0.15 & 50 & 74.5 & 0.10 & 500 & & 0.40 & 250 & & 0.55 & 350 \\
\hline \multirow[t]{3}{*}{33.85} & 0.05 & 200 & & 0.20 & 250 & & 0.50 & 200 & & 0.60 & 300 \\
\hline & 0.10 & 100 & & 0.25 & 200 & & 0.65 & 150 & & 0.65 & 300 \\
\hline & 0.20 & 50 & & 0.50 & 100 & 110.78 & 0.25 & 450 & & 0.70 & 250 \\
\hline \multirow[t]{2}{*}{37.58} & 0.05 & 250 & 77.31 & 0.15 & 350 & & 0.45 & 250 & & 0.75 & 250 \\
\hline & 0.25 & 50 & & 0.35 & 150 & & 0.55 & 200 & 151.91 & 0.40 & 500 \\
\hline \multirow[t]{4}{*}{41.38} & 0.05 & 300 & & 0.55 & 100 & & 0.70 & 150 & & 0.45 & 450 \\
\hline & 0.10 & 150 & 83.63 & 0.15 & 400 & & 0.75 & 150 & & 0.50 & 400 \\
\hline & 0.15 & 100 & & 0.20 & 300 & 117.12 & 0.25 & 500 & & 0.55 & 400 \\
\hline & 0.30 & 50 & & 0.25 & 250 & & 0.30 & 400 & & 0.60 & 350 \\
\hline \multirow[t]{2}{*}{45.02} & 0.05 & 350 & & 0.30 & 200 & & 0.35 & 350 & & 0.70 & 300 \\
\hline & 0.35 & 50 & & 0.40 & 150 & & 0.40 & 300 & & 0.80 & 250 \\
\hline \multirow[t]{4}{*}{48.19} & 0.05 & 400 & & 0.60 & 100 & & 0.50 & 250 & 164.1 & 0.45 & 500 \\
\hline & 0.10 & 200 & 87.19 & 0.15 & 450 & & 0.60 & 200 & & 0.50 & 450 \\
\hline & 0.20 & 100 & & 0.45 & 150 & & 0.65 & 200 & & 0.50 & 500 \\
\hline & 0.40 & 50 & & 0.65 & 100 & & 0.80 & 150 & & 0.55 & 450 \\
\hline \multirow[t]{3}{*}{50.58} & 0.05 & 450 & 91.07 & 0.15 & 500 & 124.24 & 0.30 & 450 & & 0.60 & 400 \\
\hline & 0.15 & 150 & & 0.20 & 350 & & 0.30 & 500 & & 0.65 & 350 \\
\hline & 0.45 & 50 & & 0.25 & 300 & & 0.35 & 400 & & 0.65 & 400 \\
\hline \multirow[t]{4}{*}{53.2} & 0.05 & 500 & & 0.30 & 250 & & 0.40 & 350 & & 0.70 & 350 \\
\hline & 0.10 & 250 & & 0.35 & 200 & & 0.45 & 300 & & 0.75 & 300 \\
\hline & 0.25 & 100 & & 0.50 & 150 & & 0.50 & 300 & & 0.75 & 350 \\
\hline & 0.50 & 50 & & 0.70 & 100 & & 0.55 & 250 & & 0.80 & 300 \\
\hline 56.12 & 0.55 & 50 & & 0.75 & 100 & & 0.60 & 250 & 178.42 & 0.55 & 500 \\
\hline \multirow[t]{5}{*}{57.7} & 0.10 & 300 & 95.31 & 0.20 & 400 & & 0.70 & 200 & & 0.60 & 450 \\
\hline & 0.15 & 200 & & 0.40 & 200 & & 0.75 & 200 & & 0.60 & 500 \\
\hline & 0.20 & 150 & & 0.55 & 150 & 132.27 & 0.35 & 450 & & 0.65 & 450 \\
\hline & 0.30 & 100 & & 0.80 & 100 & & 0.40 & 400 & & 0.70 & 400 \\
\hline & 0.60 & 50 & 99.96 & 0.20 & 450 & & 0.45 & 350 & & 0.70 & 450 \\
\hline 61.15 & 0.65 & 50 & & 0.25 & 350 & & 0.55 & 300 & & 0.75 & 400 \\
\hline \multirow[t]{3}{*}{63.03} & 0.1 & 350 & & 0.3 & 300 & & 0.65 & 250 & & 0.8 & 350 \\
\hline & 0.35 & 100 & & 0.35 & 250 & & 0.80 & 200 & & 0.80 & 400 \\
\hline & 0.70 & 50 & & 0.45 & 200 & & & & 195.49 & 0.65 & 500 \\
\hline \multirow[t]{3}{*}{65.03} & 0.15 & 250 & & 0.60 & 150 & & & & & 0.70 & 500 \\
\hline & 0.25 & 150 & & & & & & & & 0.75 & 450 \\
\hline & 0.75 & 50 & & & & & & & & 0.75 & 500 \\
\hline \multirow[t]{4}{*}{67.17} & 0.1 & 400 & & & & & & & & 0.8 & 450 \\
\hline & 0.20 & 200 & & & & & & & & 0.8 & 500 \\
\hline & 0.40 & 100 & & & & & & & & & \\
\hline & 0.80 & 50 & & & & & & & & & \\
\hline
\end{tabular}




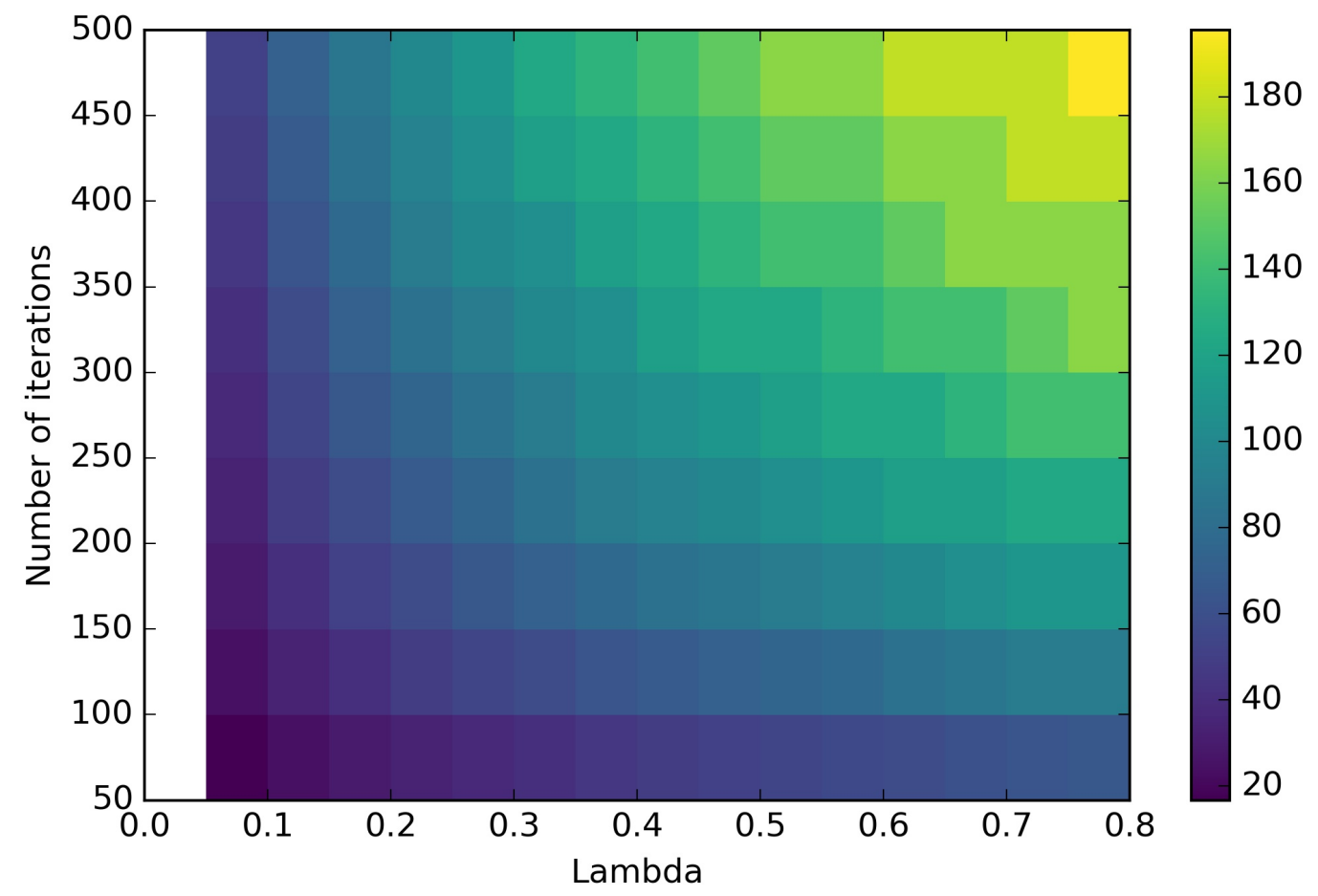

Figure A2. Laplacian diffusion cut-off wavelengths $(\mathrm{km})$ for different combinations of the number of iterations and lambdas.

\section{Appendix B}

The noise added by the SWOT simulator can be divided into two types:

- Instrument errors: There are the different types of noise that can affect the signal due to the satellite itself:

- $\quad$ Ka-Band Radar Interferometer (KaRIn)

- Roll

- Timing

- Phase

- $\quad$ Baseline dilation

Below are two example cycles of the instrument errors added by the simulator to passes 15 and 168 (Figures A3 and A4). Please note that the color-scale has been adjusted for each error type.

- Geophysical errors: In version 1 of the simulator, only the geophysical error due to the wet troposphere is implemented. Other geophysical errors include those due to the dry troposphere, the ionosphere and the sea state bias (electromagnetic bias). However, the wet troposphere is a major source of geophysical errors and it is implemented via these following two variables:

- Path delay (pd),

- Residual path delay (pd_err_1b).

Below, we show two example cycles of the geophysical errors added by the simulator to passes 15 and 168 (Figures A5 and A6). Please note that the color-scale has been adjusted for each error type. 

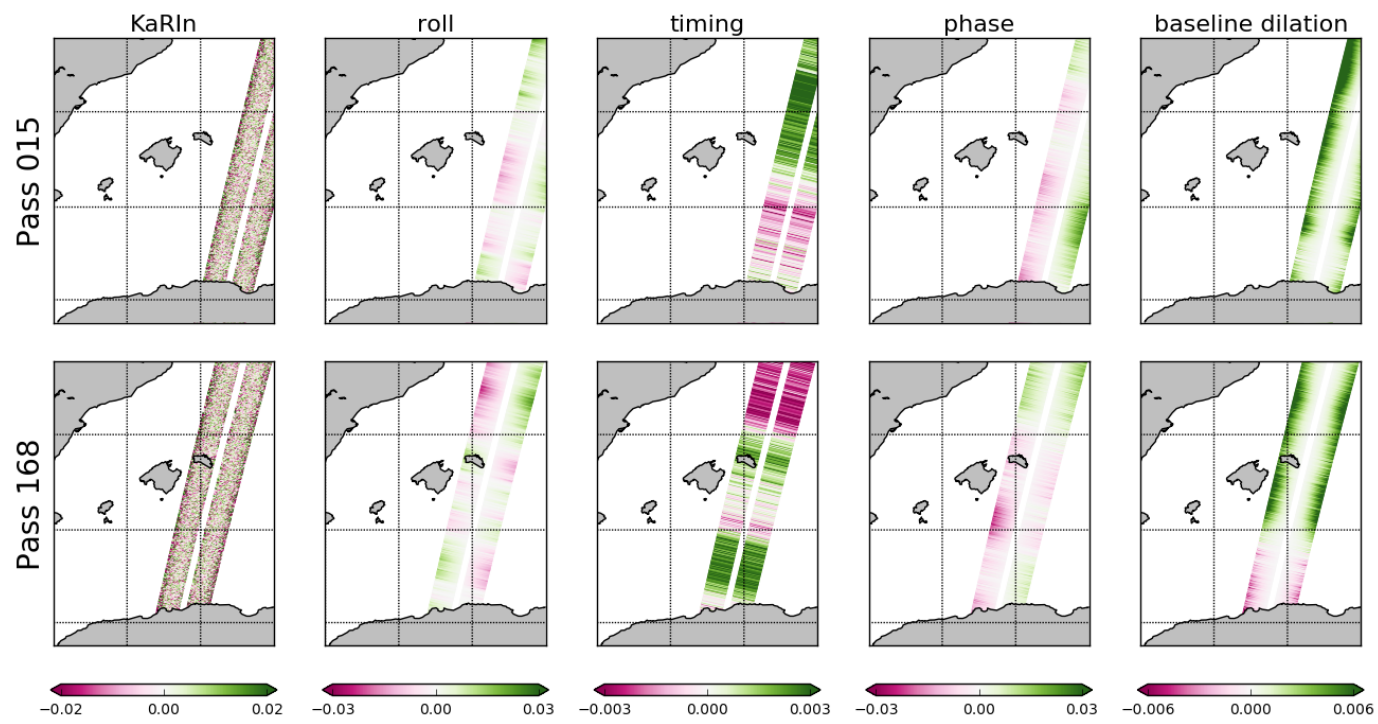

Figure A3. The different instrument noise types (m) for passes 15 pass 168 over cycle 2 are shown.
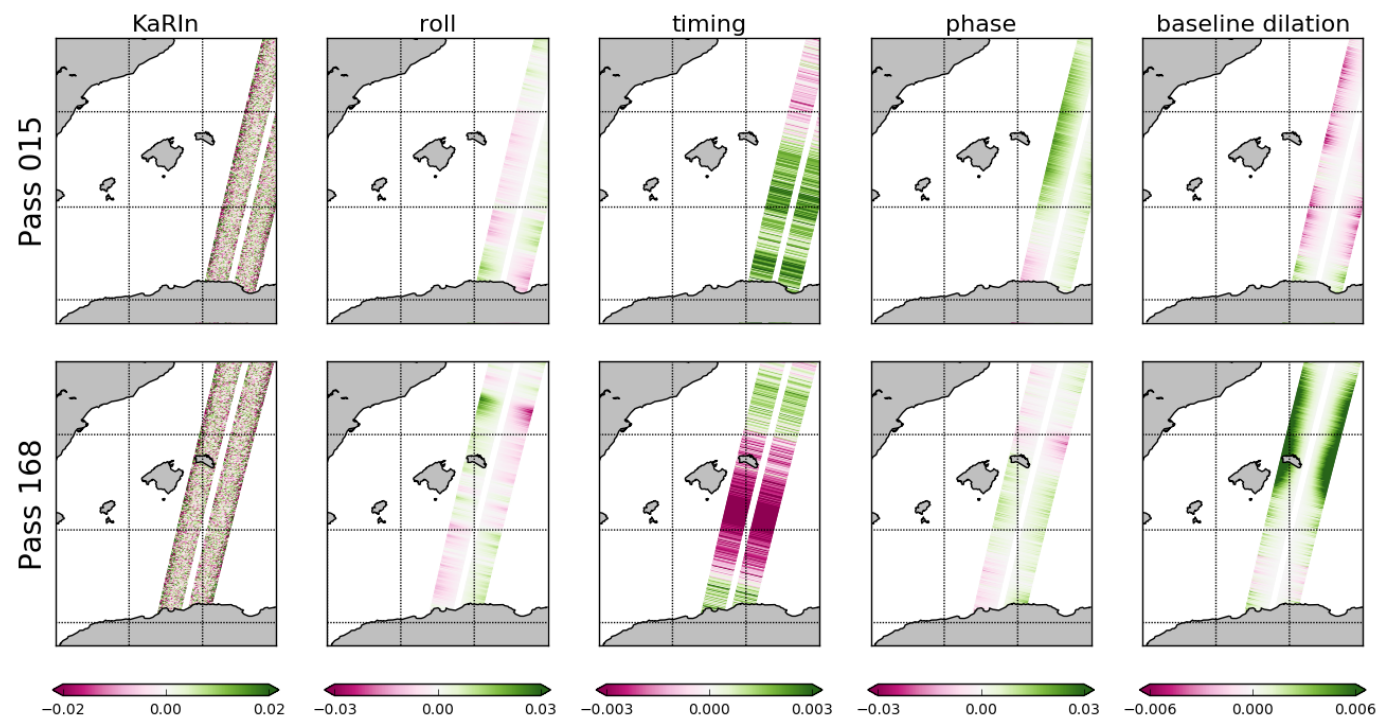

Figure A4. The different instrument noise types (m) for passes 15 and 168 over cycle 30 are shown. 

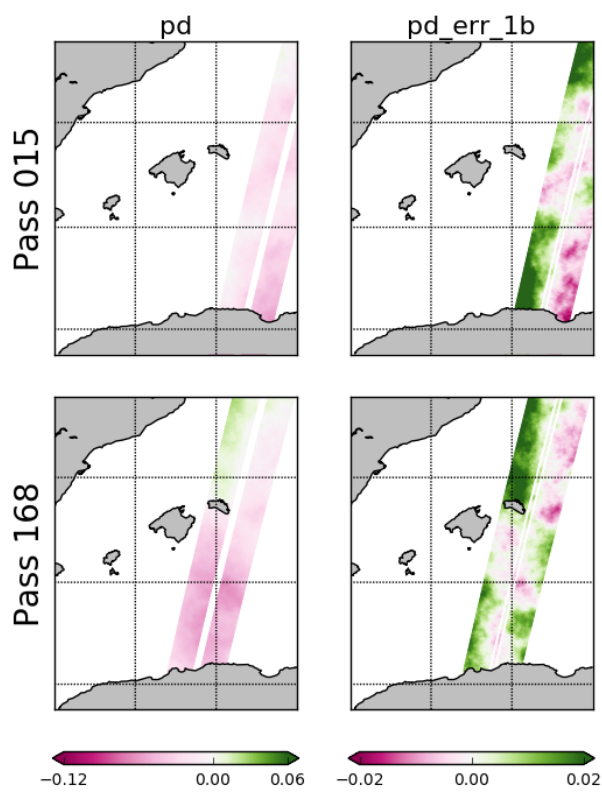

Figure A5. The different geophysical errors (m) for passes 15 and 168 over cycle 2 are shown.
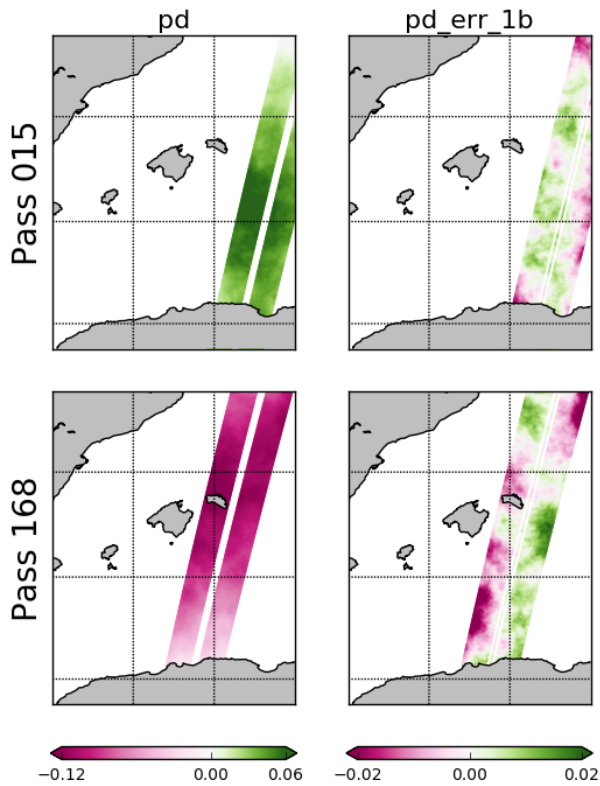

Figure A6. The different geophysical errors (m) for passes 15 and 168 over cycle 30 are shown.

For more details on instrument and geophysical errors, see [30,50].

\section{References}

1. Alsdorf, D.; Mognard, N.; Lettenmaier, D. Remote Sensing of Surface Water and Recent Developments in the SWOT Mission. In Proceedings of the Session H21J-06, AGU Fall Meeting, San Francisco, CA, USA, 5-9 December 2011.

2. Fu, L.L.; Morrow, R. A next generation altimeter for mapping the sea surface variability: Opportunities and challenges. In Proceedings of the 48th Liege Colloquium on Ocean Dynamics, Liège, Belgium, 23-27 May 2016. 
3. Lee, H.; Biancamaria, S.; Alsdorf, D.; Andreadis, K.; Clark, E.; Durand, M.; Jung, H.C.; Lettenmaier, D.; Mognard, N.; Rodríguez, E.; et al. Capability of SWOT to Measure Surface Water Storage Change. In Proceedings of the Towards high-resolution of oceans dynamics and terrestrial water from space meeting, Lisbon, Portugal, 21-22 October 2010.

4. Rodríguez, E. The Surface Water and Ocean Topography (SWOT) Mission. In Proceedings of the OSTST (Ocean Surface Topography Science Team) meeting, Lisbon, Portugal, 18-20 October 2010.

5. Pujol, M.I.; Dibarboure, G.; Le Traon, P.Y.; Klein, P. Using high-resolution altimetry to observe mesoscale signals. J. Atmos. Ocean. Technol. 2012, 29, 1409-1416, doi:10.1175/JTECH-D-12-00032.1.

6. Rodríguez, E. Surface Water and Ocean Topography Mission Project Science Requirements Document. Jet Propulsion Laboratory, California Institute of Technology, JPL D-61923; March 2016; 28p. Available online: https:/ / swot.jpl.nasa.gov/documents.htm (accessed on 12 April 2018).

7. Rogé, M.; Morrow, R.; Ubelmann, C.; Dibarboure, G. Using a dynamical advection to reconstruct a part of the SSH evolution in the context of SWOT, application to the Mediterranean Sea. Ocean Dyn. 2017, 67, 1047-1066.

8. Cipollini, P.; Calafat, F.M.; Jevrejeva, S.; Melet, A.; Prandi, P. Monitoring Sea Level in the Coastal Zone with Satellite Altimetry and Tide Gauges. Surv. Geophys. 2017, 38, 33-57.

9. Fu, L.L.; Ferrari, R. Observing Oceanic Submesoscale Processes From Space. Eos Trans. Am. Geophys. Union 2008, 89, 488, doi:10.1109/IGARSS.2011.6049757.

10. Dufau, C.; Orsztynowicz, M.; Dibarboure, G.; Morrow, R.; Le Traon, P.Y. Mesoscale resolution capability of altimetry: Present and future. J. Geophys. Res. Ocean. 2016, doi:10.1002/2015JC010904.

11. Chelton, D.B.; Schlax, M.G.; Samelson, R.M.; de Szoeke, R.A. Global observations of large oceanic eddies. Geophys. Res. Lett. 2007, 34, doi:10.1029/2007GL030812.

12. Fu, L.L.; Ubelmann, C. On the transition from profile altimeter to swath altimeter for observing global ocean surface topography. J. Atmos. Ocean. Technol. 2014, 31, 560-568, doi:10.1175/JTECH-D-13-00109.1.

13. Mémery, L.; Olivier, F. Primary production and export fluxes at the Almeria-Oran front: A numerical study. In Proceedings of the EGS-AGU-EUG Joint Assembly, Nice, France, 6-11 April, 2003.

14. Lévy, M.; Klein, P.; Treguier, A.M. Impact of sub-mesoscale physics on production and subduction of phytoplankton in an oligotrophic regime. J. Mar. Res. 2001, 59, 535-565.

15. Lapeyre, G.; Klein, P. Impact of the small-scale elongated filaments on the oceanic vertical pump. J. Mar. Res. 2006, 64, 835-851.

16. Omand, M.M.; D'Asaro, E.A.; Lee, C.M.; Perry, M.J.; Briggs, N.; Cetinić, I.; Mahadevan, A. Eddy-driven subduction exports particulate organic carbon from the spring bloom. Science 2015, 348, 222-225.

17. McGillicuddy, D.J.; Anderson, L.A.; Bates, N.R.; Bibby, T.; Buesseler, K.O.; Carlson, C.A.; Davis, C.S.; Ewart, C.; Falkowski, P.G.; Goldthwait, S.A.; et al. Eddy/wind interactions stimulate extraordinary mid-ocean plankton blooms. Science 2007, 316, 1021-1026.

18. Allen, J.; Smeed, D.; Tintoré, J.; Ruiz, S. Mesoscale subduction at the almeria-oran front: Part 1: Ageostrophic flow. J. Mar. Syst. 2001, 30, 263-285.

19. Ruiz, S.; Pascual, A.; Garau, B.; Faugère, Y.; Alvarez, A.; Tintoré, J. Mesoscale dynamics of the Balearic Front, integrating glider, ship and satellite data. J. Mar. Syst. 2009, 78, S3-S16.

20. Pascual, A.; Ruiz, S.; Olita, A.; Troupin, C.; Claret, M.; Casas, B.; Mourre, B.; Poulain, P.M.; Tovar-Sanchez, A.; Capet, A.; et al. A multiplatform experiment to unravel meso-and submesoscale processes in an intense front (alborex). Front. Mar. Sci. 2017, 4, 39.

21. Bethoux, J.; Gentili, B.; Morin, P.; Nicolas, E.; Pierre, C.; Ruiz-Pino, D. The Mediterranean Sea: A miniature ocean for climatic and environmental studies and a key for the climatic functioning of the North Atlantic. Progress Oceanogr. 1999, 44, 131-146.

22. Malanotte-Rizzoli, P.; Artale, V.; Borzelli-Eusebi, G.L.; Brenner, S.; Crise, A.; Gacic, M.; Kress, N.; Marullo, S.; d'Alcalà, M.R.; Sofianos, S.; et al. Physical forcing and physical/biochemical variability of the Mediterranean Sea: A review of unresolved issues and directions for future research. Ocean Sci. 2014, 10, 281, doi:10.5194/os-10-281-2014.

23. Robinson, A.R.; Leslie, W.G.; Theocharis, A.; Lascaratos, A. Mediterranean sea circulation. In Ocean Currents: A Derivative of the Encyclopedia of Ocean Sciences; Elsevier: Amsterdam, The Netherlands, 2001; pp. 1689-1705.

24. Hallberg, R. Using a resolution function to regulate parameterizations of oceanic mesoscale eddy effects. Ocean Model. 2013, 72, 92-103, doi:10.1016/j.ocemod.2013.08.007. 
25. Escudier, R.; Renault, L.; Pascual, A.; Brasseur, P.; Chelton, D.; Beuvier, J. Eddy properties in the Western Mediterranean Sea from satellite altimetry and a numerical simulation. J. Geophys. Res. 2016, 121, 3990-4006, doi:10.1002/2015JC011371.

26. Chelton, D.B.; Deszoeke, R.A.; Schlax, M.G.; El, K.; And, N.; Siwertz, N. Geographical Variability of the First Baroclinic Rossby Radius of Deformation. J. Phys. Oceanogr. 1998, 28, 433-460.

27. Nurser, A.J.G.; Bacon, S. Arctic Ocean Rossby radius Eddy length scales and the Rossby radius in the Arctic Ocean Arctic Ocean Rossby radius. Ocean Sci. Discuss. 2013, 10, 1807-1831, doi:10.5194/osd-10-1807-2013.

28. Wang, J.; Fu, L.L.; Qiu, B.; Menemenlis, D.; Farrar, J.T.; Chao, Y.; Thompson, A.F.; Flexas, M.M. An Observing System Simulation Experiment for the Calibration and Validation of the Surface Water Ocean Topography Sea Surface Height Measurement Using In Situ Platforms. J. Atmos. Ocean. Technol. 2018, 35, 281-297, doi:10.1175/JTECH-D-17-0076.1.

29. Gaultier, L.; Ubelmann, C.; Fu, L.L. SWOT Simulator Documentation; Tech. Rep. 1.0.0, Jet Propulsion Laboratory, California Institute of Technology: Pasadena, CA, USA, 2015.

30. Gaultier, L.; Ubelmann, C.; Fu, L.L. The challenge of using future SWOT data for oceanic field reconstruction. J. Atmos. Ocean. Technol. 2016, 33, 119-126, doi:10.1175/JTECH-D-15-0160.1.

31. Juza, M.; Mourre, B.; Renault, L.; Gómara, S.; Sebastián, K.; Lora, S.; Beltran, J.; Frontera, B.; Garau, B.; Troupin, C.; et al. SOCIB operational ocean forecasting system and multi-platform validation in the Western Mediterranean Sea. J. Oper. Oceanogr. 2016, 9, s155-s166.

32. Shchepetkin, A.F.; McWilliams, J.C. The regional oceanic modeling system (ROMS): A split-explicit, free-surface, topography-following-coordinate oceanic model. Ocean Model. 2005, 9, 347-404.

33. Sonka, M.; Hlavac, V.; Boyle, R. Image Processing, Analysis, and Machine Vision; Cengage Learning: Boston, MA, USA, 2014.

34. Aubert, G.; Kornprobst, P. Mathematical Problems in Image Processing: Partial Differential Equations and the Calculus of Variations; Springer Science \& Business Media: Berlin, Germany, 2006; Volume 147.

35. Escudier, R.; Mourre, B.; Juza, M.; Tintoré, J. Subsurface circulation and mesoscale variability in the Algerian subbasin from altimeter-derived eddy trajectories. J. Geophys. Res. Ocean. 2016, 121, 6310-6322, doi:10.1002/2016JC011760.

36. Gunturk, B.K.; Li, X. Image Restoration: Fundamentals and Advances; CRC Press: Boca Raton, FL, USA, 2012.

37. Klein, P.; Morrow, R.; Samelson, R.; Chelton, D.; Lapeyre, G.; Fu, L.; Qiu, B.; Ubelmann, C.; Le Traon, P.Y.; Capet, X.; et al. Mesoscale/Sub-Mesoscale Dynamics in the Upper Ocean. 2015. NASA Surface Water and Ocean Topography (SWOT). Available online: https:/ / www.aviso.altimetry.fr/fileadmin/documents / missions/Swot/WhitePaperSWOTSubmesoscale.pdf (accessed on 12 April 2018).

38. Ruggiero, G.; Cosme, E.; Brankart, J.; Sommer, J.L.; Ubelmann, C. An efficient way to account for observation error correlations in the assimilation of data from the future SWOT High-Resolution altimeter mission. J. Atmos. Ocean. Technol. 2016, 33, 2755-2768, doi:10.1175/JTECH-D-16-0048.1.

39. Pujol, M.I.; Faugere, Y.; Taburet, G.; Dupuy, S.; Pelloquin, C.; Ablain, M.; Picot, N. DUACS DT2014: The new multi-mission altimeter data set reprocessed over 20 years. Ocean Sci. 2016, 12, 1067-1090.

40. Ubelmann, C.; Klein, P.; Fu, L.L. Dynamic interpolation of sea surface height and potential applications for future high-resolution altimetry mapping. J. Atmos. Ocean. Technol. 2015, 32, 177-184.

41. Fablet, R.; Verron, J.; Mourre, B.; Chapron, B.; Pascual, A. Improving mesoscale altimetric data from a multitracer convolutional processing of standard satellite-derived products. IEEE Trans. Geosci. Remote Sens. 2018, doi:10.1109/TGRS.2017.2750491.

42. Lguensat, R.; Viet, P.H.; Sun, M.; Chen, G.; Fenglin, T.; Chapron, B.; Fablet, R. Data-driven Interpolation of Sea Level Anomalies Using Analog Data Assimilation. 2017. Available online: https://hal.archivesouvertes.fr/hal-01609851 (accessed on 12 April 2018).

43. Moro, M.D.; Brankart, J.M.; Brasseur, P.; Verron, J. Exploring image data assimilation in the prospect of high-resolution satellite oceanic observations. Ocean Dyn. 2017, 67, 875-895.

44. Mason, E.; Pascual, A.; McWilliams, J.C. A new sea surface height-based code for oceanic mesoscale eddy tracking. J. Atmos. Ocean. Technol. 2014, 31, 1181-1188, doi:10.1175/JTECH-D-14-00019.1.

45. Conti, D.; Orfila, A.; Mason, E.; Sayol, J.M.; Simarro, G.; Balle, S. An eddy tracking algorithm based on dynamical systems theory. Ocean Dyn. 2016, 66, 1415-1427, doi:10.1007/s10236-016-0990-7. 
46. D’Ortenzio, F.; Iudicone, D.; de Boyer Montegut, C.; Testor, P.; Antoine, D.; Marullo, S.; Santoleri, R.; Madec, G. Seasonal variability of the mixed layer depth in the Mediterranean Sea as derived from in situ profiles. Geophys. Res. Lett. 2005, 32, doi:10.1029/2005GL022463.

47. Houpert, L.; Testor, P.; de Madron, X.D.; Somot, S.; D'ortenzio, F.; Estournel, C.; Lavigne, H. Seasonal cycle of the mixed layer, the seasonal thermocline and the upper-ocean heat storage rate in the Mediterranean Sea derived from observations. Progress Oceanogr. 2015, 132, 333-352.

48. Qiu, B.; Chen, S.; Klein, P.; Ubelmann, C.; Fu, L.; Sasaki, H. Reconstructability of 3-Dimensional upper ocean circulation from SWOT Sea Surface Height measurements (early online release). J. Phys. Oceanogr. J. Phys. Ocean. 2016, 46, 947-963, doi:10.1175/JPO-D-15-0188.1.

49. Lindstrom, E.; Cherchal, S.; Fu, L.L.; Morrow, R.; Pavelsky, T.; Cretaux, J.F.; Vaze, P.; Lafon, T.; Coutin-Faye, S.; Amen, L.; et al. Summary Report of the 2nd SWOT Science Team Meeting 2017; Techreport; Meteo-France Conference Centre: Touloue, France, 2017.

50. Esteban-Fernandez, D. SWOT Project: Mission Performance and Error Budget Document. Jet Propulsion Laboratory, California Institute of Technology, JPL D-79084. April 2017; 117p. Available online: https: / /swot.jpl.nasa.gov/documents.htm (accessed on 12 April 2018).

(C) 2018 by the authors. Licensee MDPI, Basel, Switzerland. This article is an open access article distributed under the terms and conditions of the Creative Commons Attribution (CC BY) license (http://creativecommons.org/licenses/by/4.0/). 